\title{
Recursos de la zona béntica de la bahía de Sechura
}

\section{Resources benthic of the bay of Sechura}

\author{
Juan Tume Ruiz*, Alejandro Ibaceta Cipirán**, Miguel Cortez Oyola***, \\ Joseph Santisteban Atarama****
}

http://dx.doi.org/10.21503/CienciayDesarrollo.2012.v15i1.02

RESUMEN

La bahía de Sechura se ubica en la costa norte del Perú, en las coordenadas $05^{\circ} 18^{\prime} 46^{\prime \prime}$ y $05^{\circ} 50^{\prime} 33^{\prime \prime}$ de latitud sur, está delimitada por el norte por la Punta Gobernador y Punta Aguja por el sur, y los paralelos $80^{\circ} 50^{\prime} 59^{\prime \prime}$ y $81^{\circ} 04^{\prime} 80^{\prime \prime}$ de longitud oeste, a $49 \mathrm{~km}$ al sur de la ciudad de Piura.

La bahía es una de las principales zonas de obtención de recursos pesqueros; pero progresivamente los relaves, los desperdicios de la población, plantas industriales de harina de pescado, de congelado, de concentrado de fosfato y las exploraciones petroleras con posibilidades de producción la están contaminando.

Ello nos ha llevado a identificar las especies bentónicas de cuyo registro existe escasa información. Hemos registrado ciento cinco especies.

Palabras clave: Recursos bentósos.

\section{ABSTRAC}

Sechura Bay is located on the northern coast of Peru, at coordinates $05^{\circ} 18^{\prime} 46^{\prime \prime}$ and $05^{\circ} 50^{\prime} 33^{\prime \prime}$ of south latitude, is bounded on the north by Punta Gobernador and Punta Aguja on the south, and parallels $80^{\circ} 50^{\prime} 59^{\prime \prime}$ and $81^{\circ} 04^{\prime} 80^{\prime \prime}$ of west longitude, 49 kilometers south of Piura city.

The bay is one of the main areas of fishery resources production, but the tailings, the waste of the population, industries such as fishmeal, frozen, concentrate of phosphate and oil exploration with the production possibilities are polluting it gradually.

This leads us to identify the benthic species whose registry has limited information. We have registered one hundred and five species.

Key words: Benthos resources.

\section{INTRODUCCIÓN}

La bahía de Sechura es una de las principales zonas de obtención de recursos pesqueros, donde se destacan algunos recursos pelágicos como la anchoveta (Engraulis ringens), el jurel (Trachurus picturatus murphyi) y la muy conocida caballa sechurana (Scomber japonicus peruanus). La bahía ofrece también recursos demersales comola cabrilla sechurana (Paralabrax humeralis), el lenguado (Paralichthys adspersus) y el mero (Epinephelus labriformis). Actualmente han adquirido gran importancia los recursos bentónicos del Perú, en especial la concha de abanico (Argopecten purpuratus). No obstante, no existen informes de la mayoria de especies, lo que hace impostergable e importante su registro, más aún frente a los riesgos de extinción por la contaminación en la bahía.

\footnotetext{
* Ing. Pesquero. Docente de la Facultad de Ingeniería Pesquera de la Universidad Nacional de Piura, con estudios de post Grado en Ciencias del Mar. Docente en la UAP e-mail: delfin_jtr@hotmail.com

** Blgo. Alejandro ibaceta Cipirán (alibaci49@hotmail.com). Ha trabajado en IMARPE. Asesor de las Asociaciones de Pescadores y Maricultores de la Bahía de Sechura.

*** Blgo. Miguel Cortez Oyola (mangelcort@hotmail.com). Docente de la Escuela de Biología de la Universidad Nacional de Piura, experto en Taxonomia de invertebrados. Con estudios de post Grado en Ciencias del Mar

${ }^{* * * *}$ Ing. Joseph Santisteban Atarama (joseph_11222@hotmail.com). Ingeniero Pesquero, especialista en Acuicultura
} 
El estudio se orientó a responder cuáles son las especies bentónicas de la bahía de Sechura. Para ello, se partió de la recolección y registro en toda su extensión, trabajo de exploración e identificación que se complementó con la revisión de la colección de especies que el señor Juan Abad Pardo, ex técnico del IMARPE, había coleccionado por más de veinte años.
Los recursos bentónicos, como la concha de abanico, se han constituido en los más rentables y factibles de cultivar a lo largo de la costa, no solo por haberse resuelto aspectos técnicos de su manejoy cultivo, sino también por la importancia que tienen como productos de exportación y como recursos para la implementación de proyectos acuícolas en el sector pesquero artesanal.

\section{RESULTADOS}

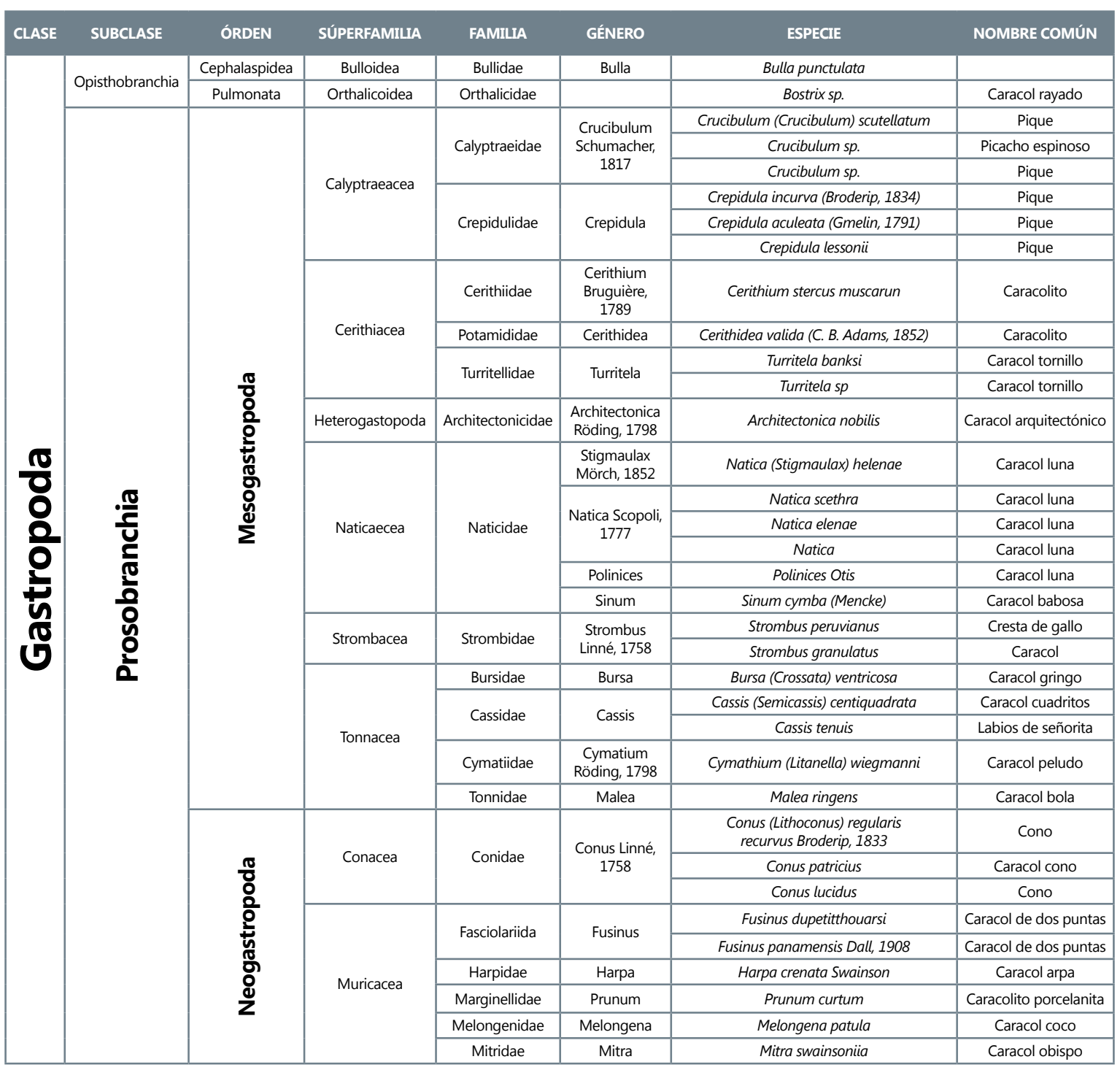




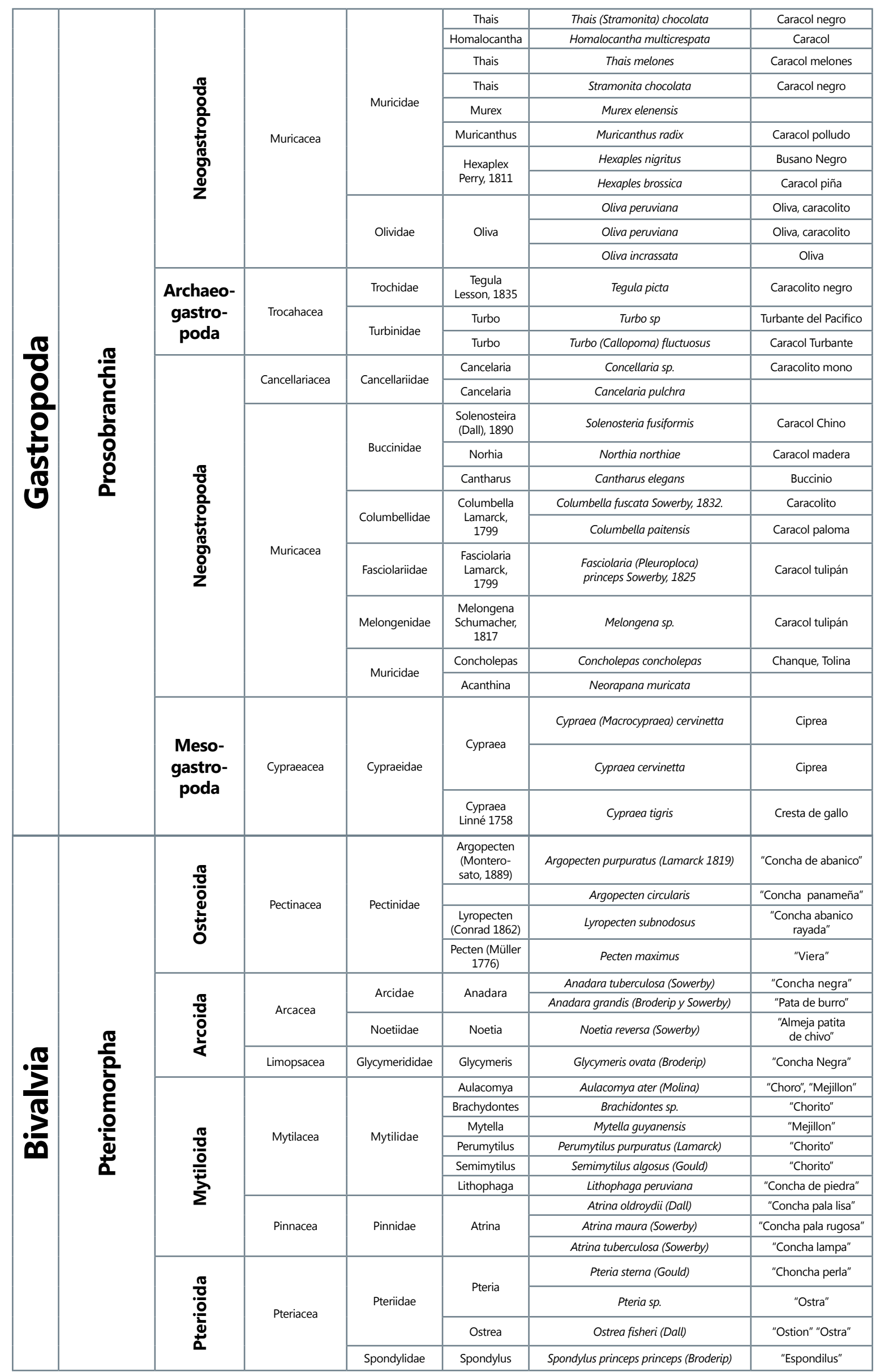




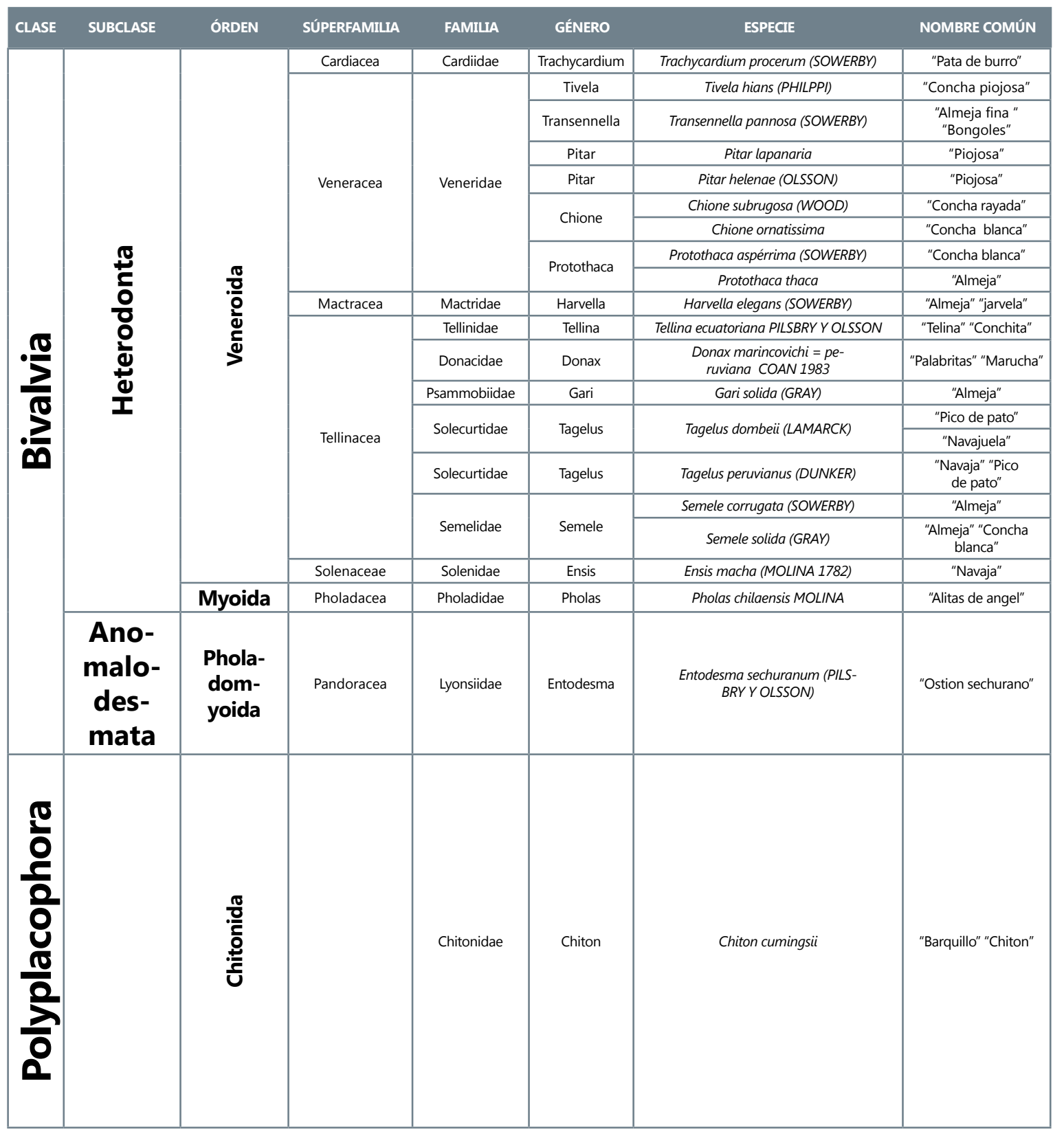




\section{IMÁGENES DE ESPECIES ENCONTRADAS}

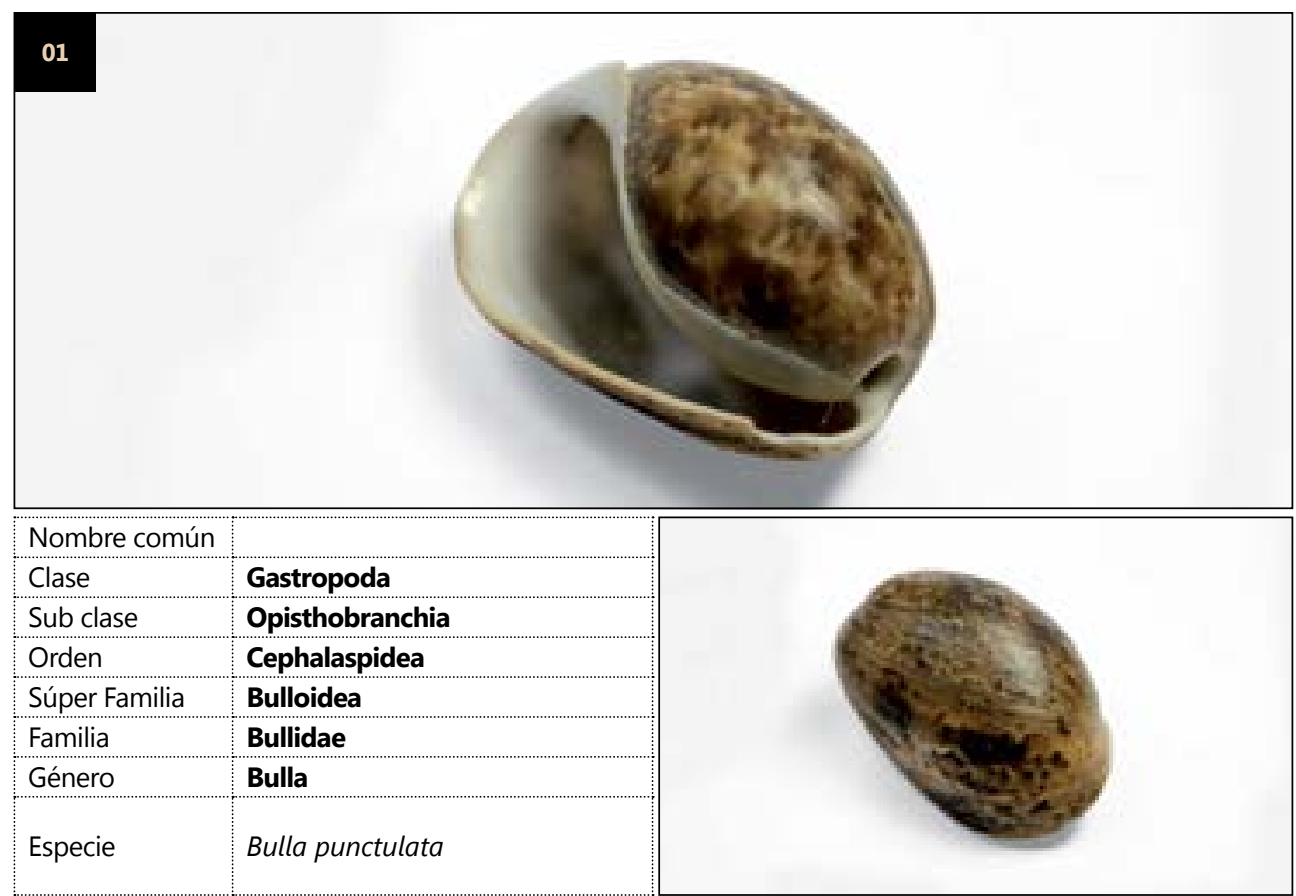

\section{2}

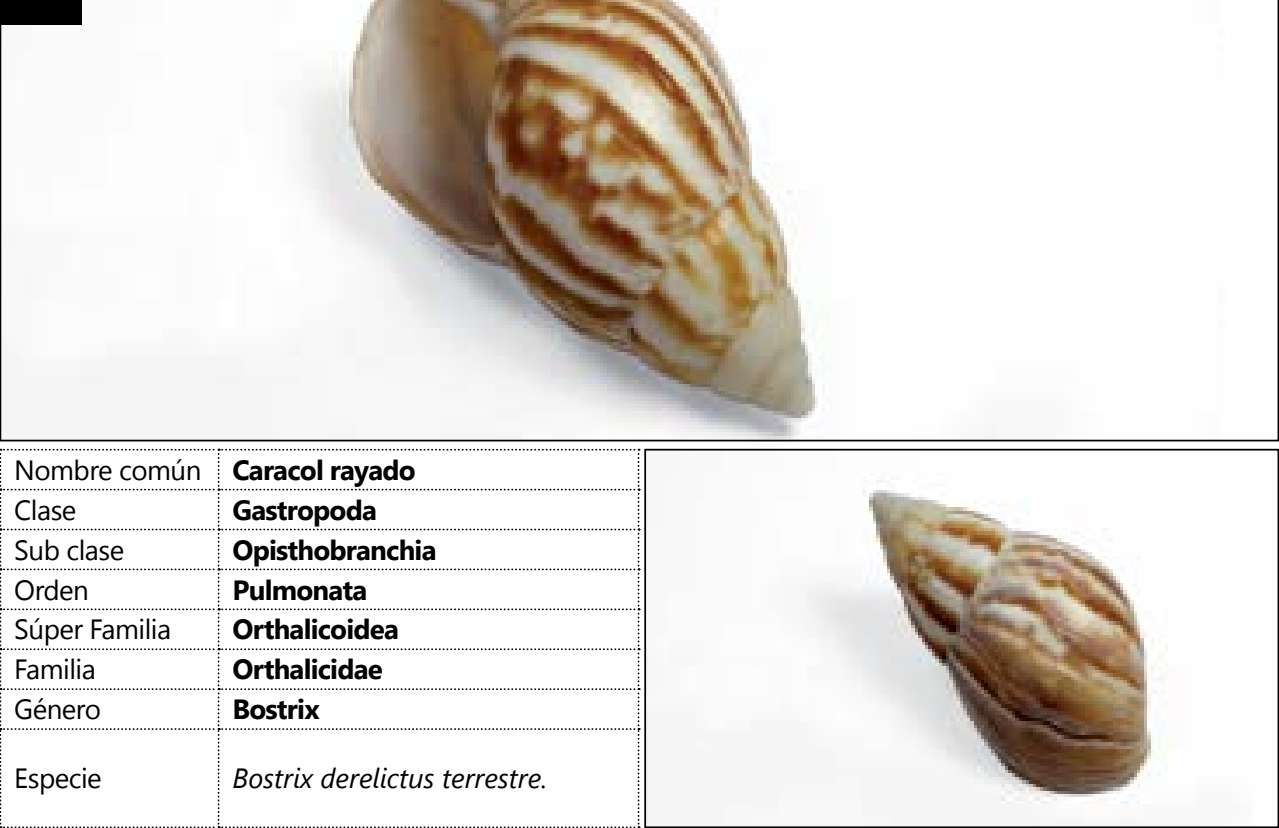




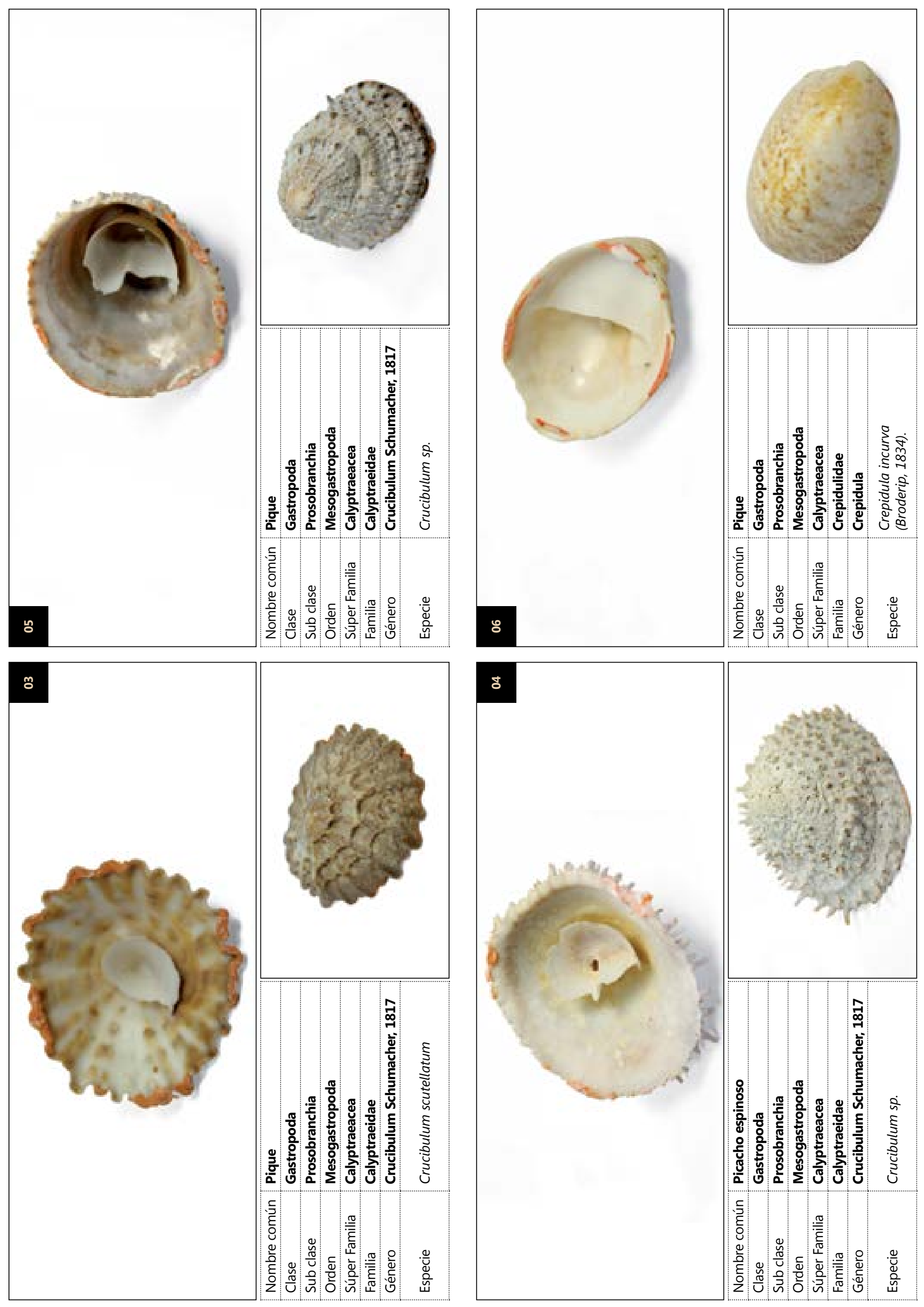




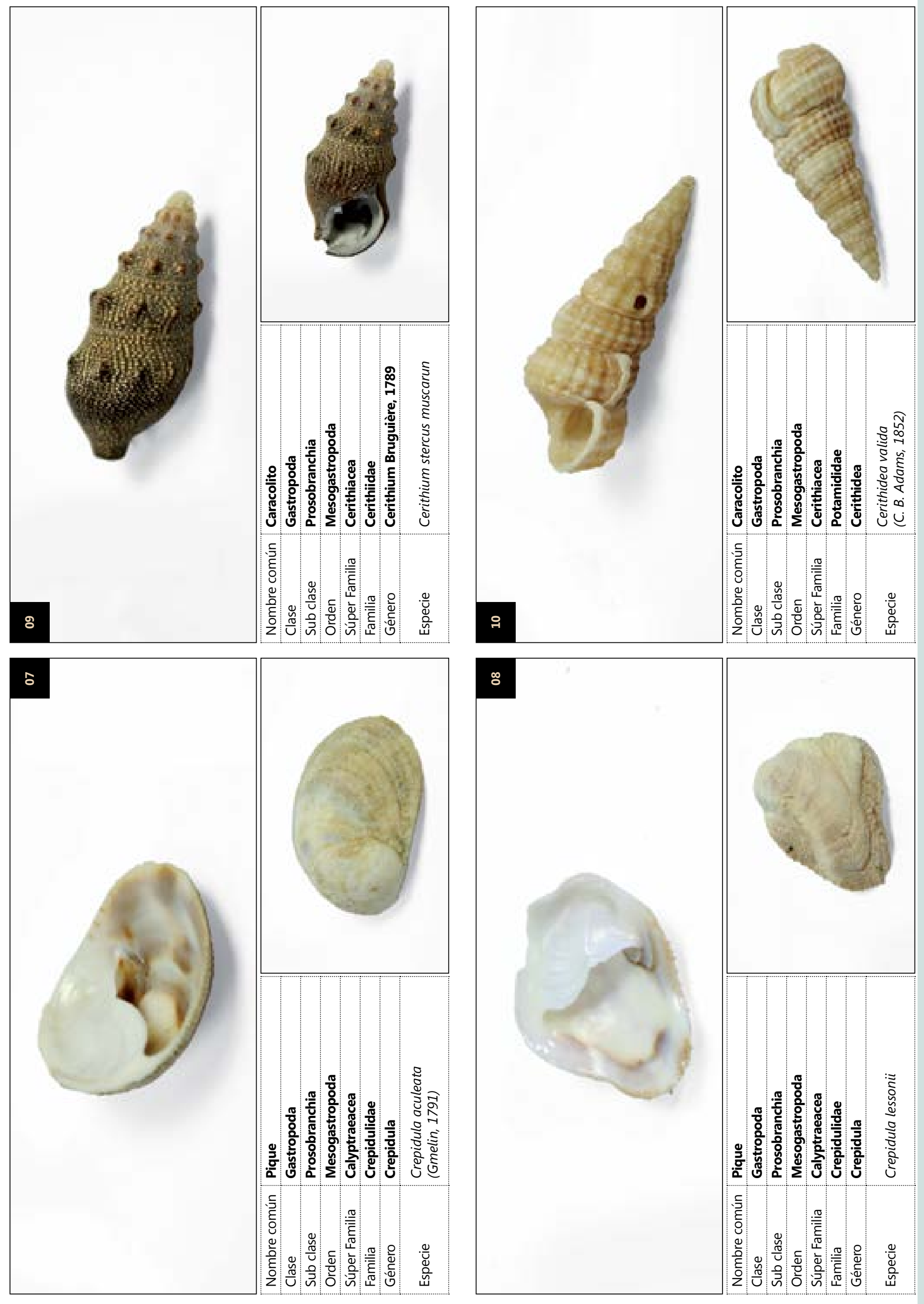




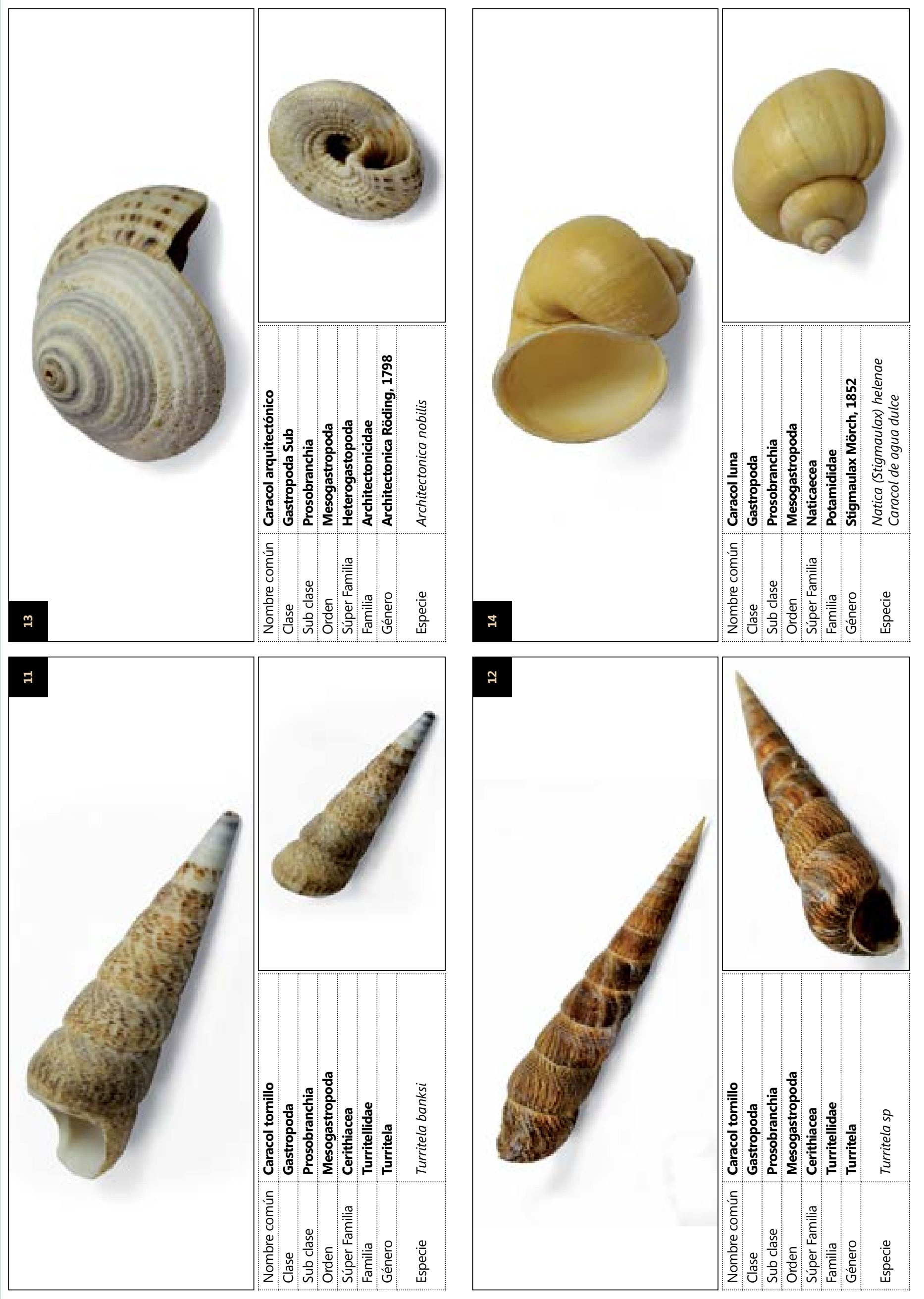




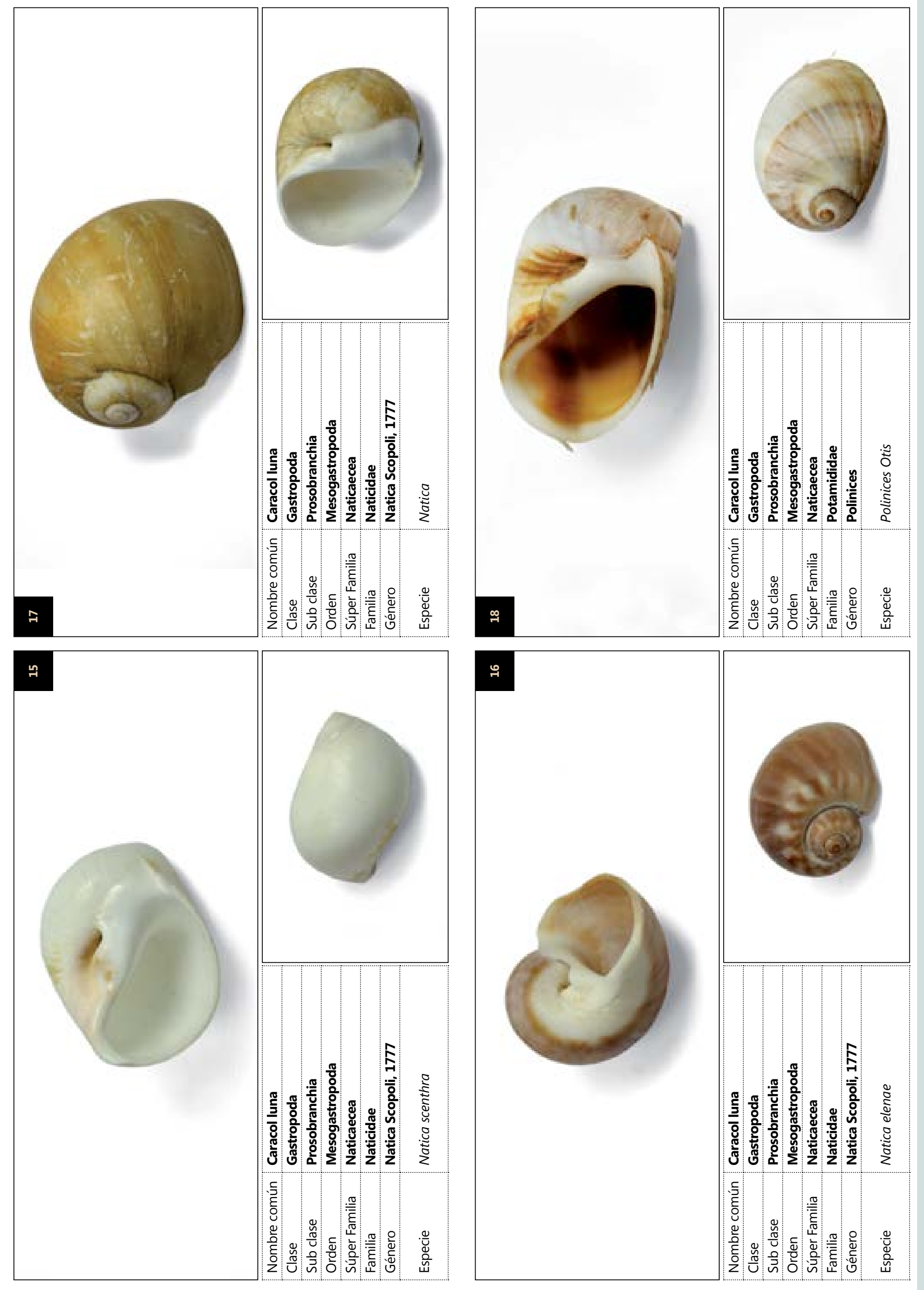




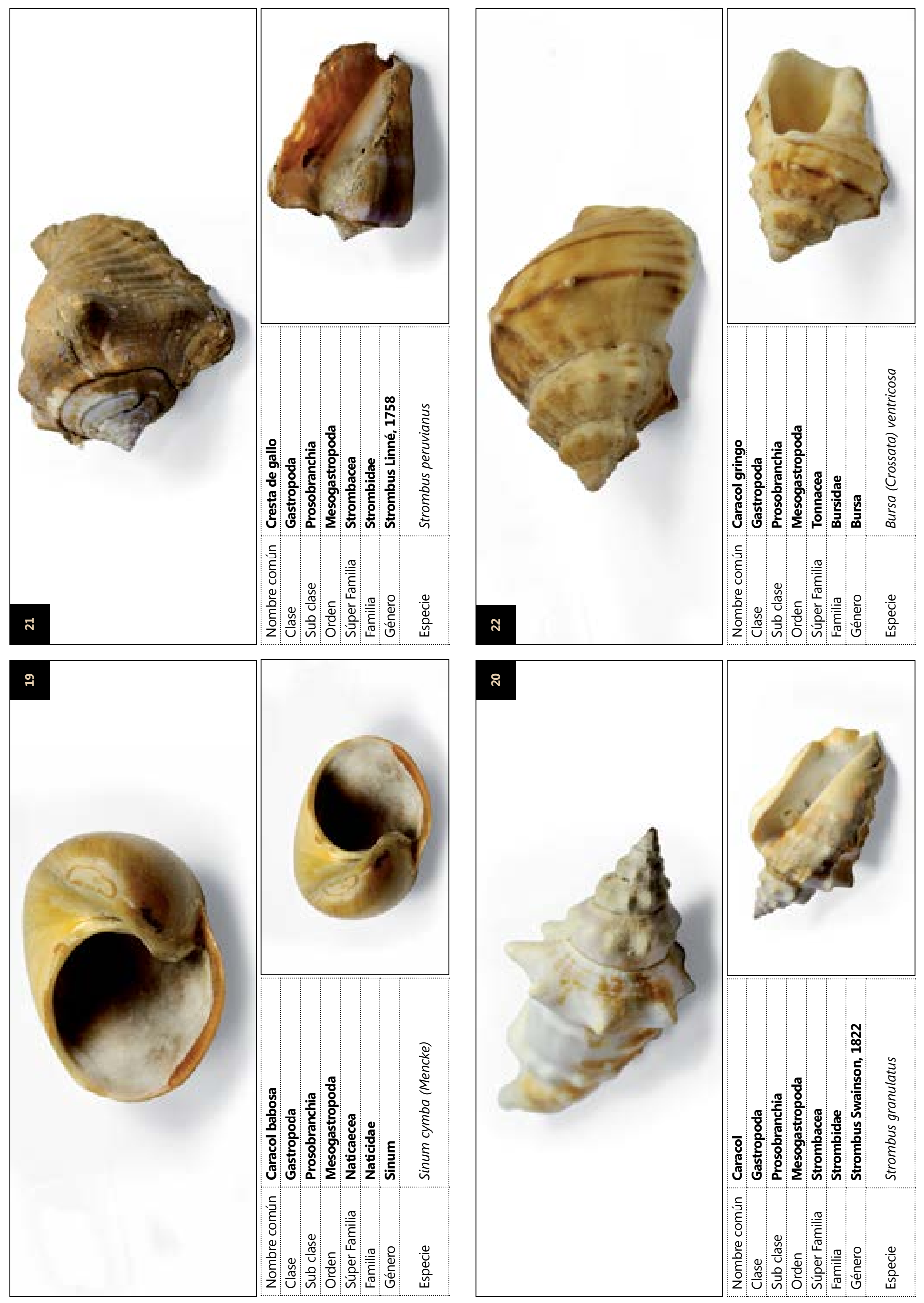




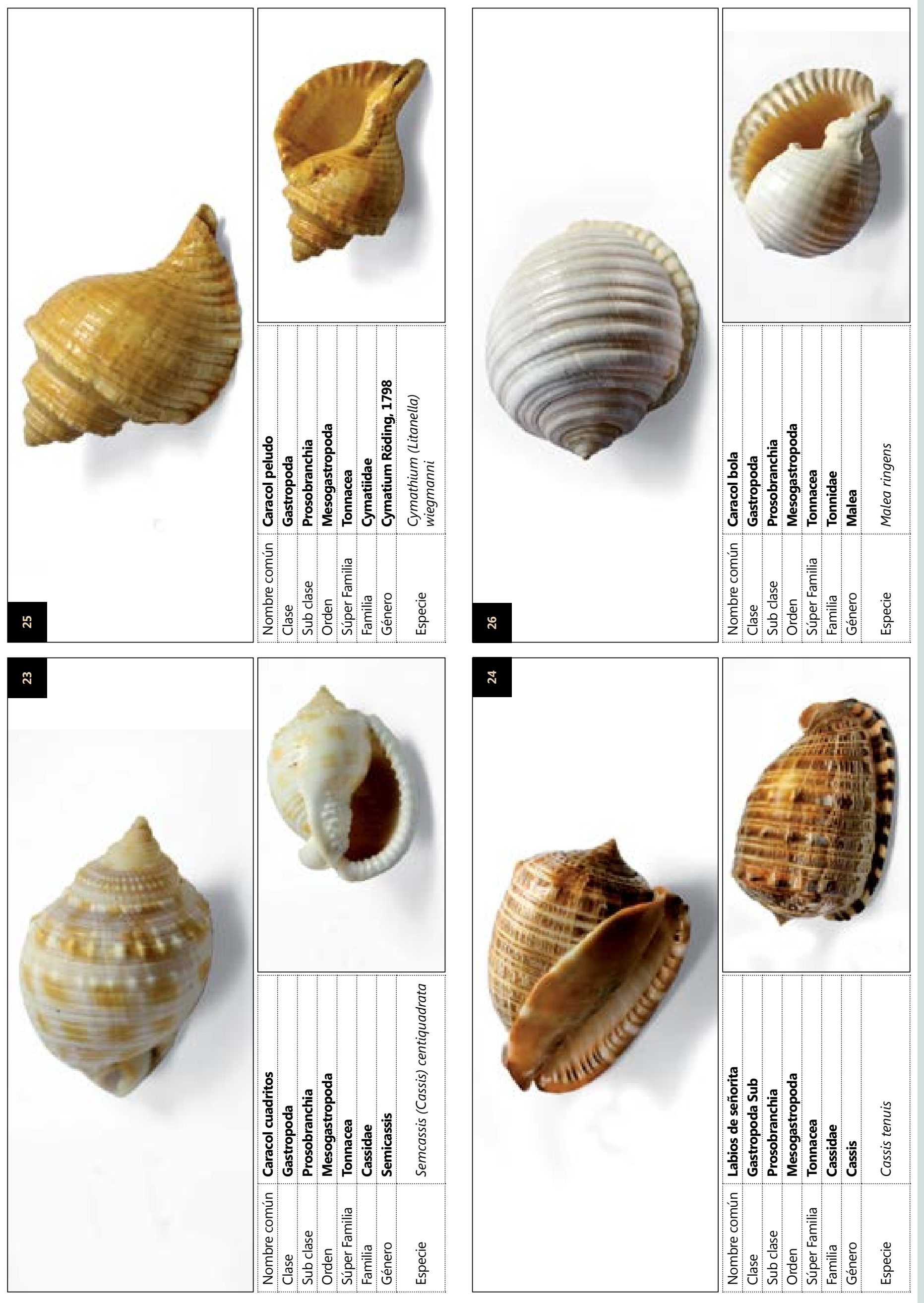




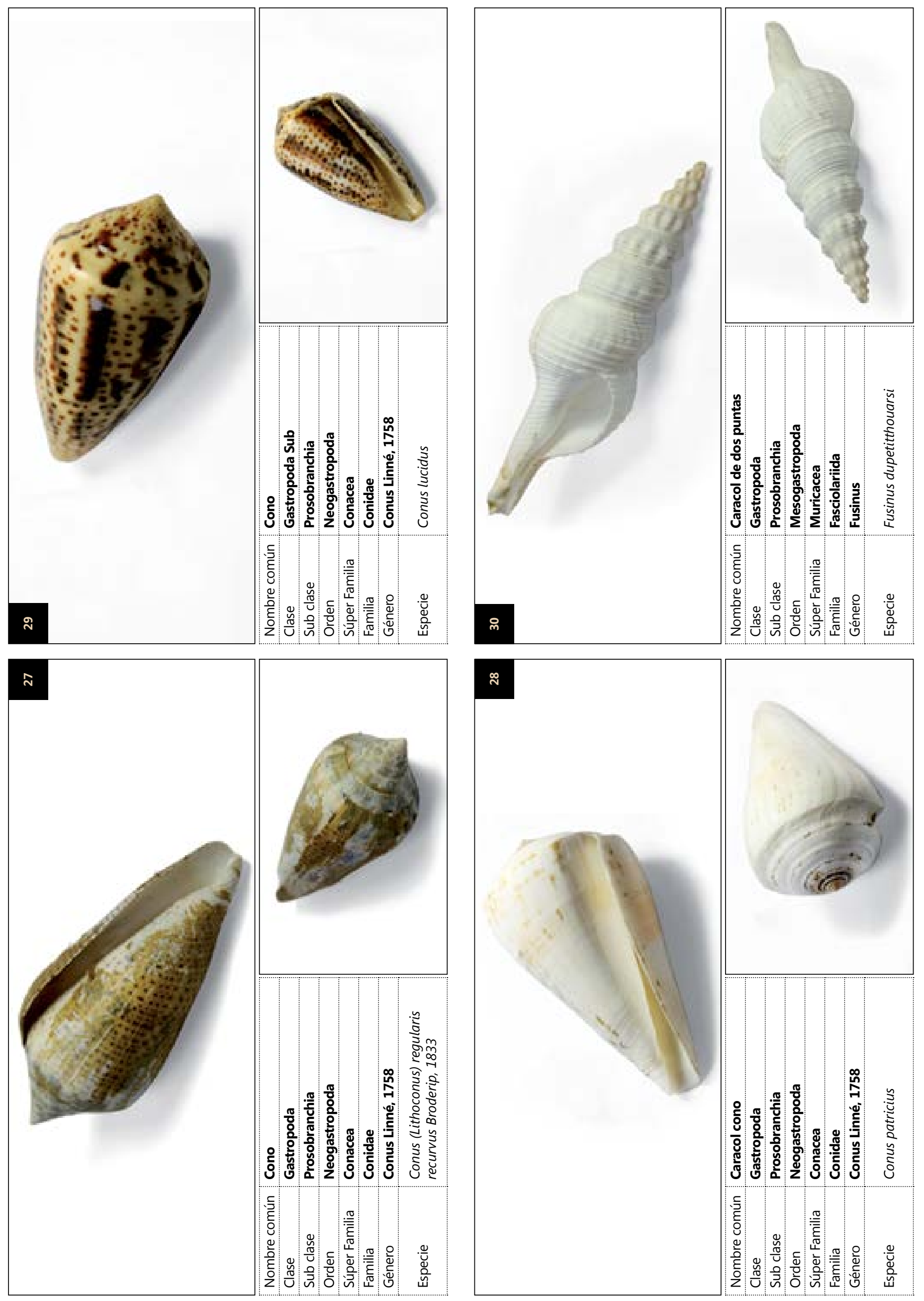




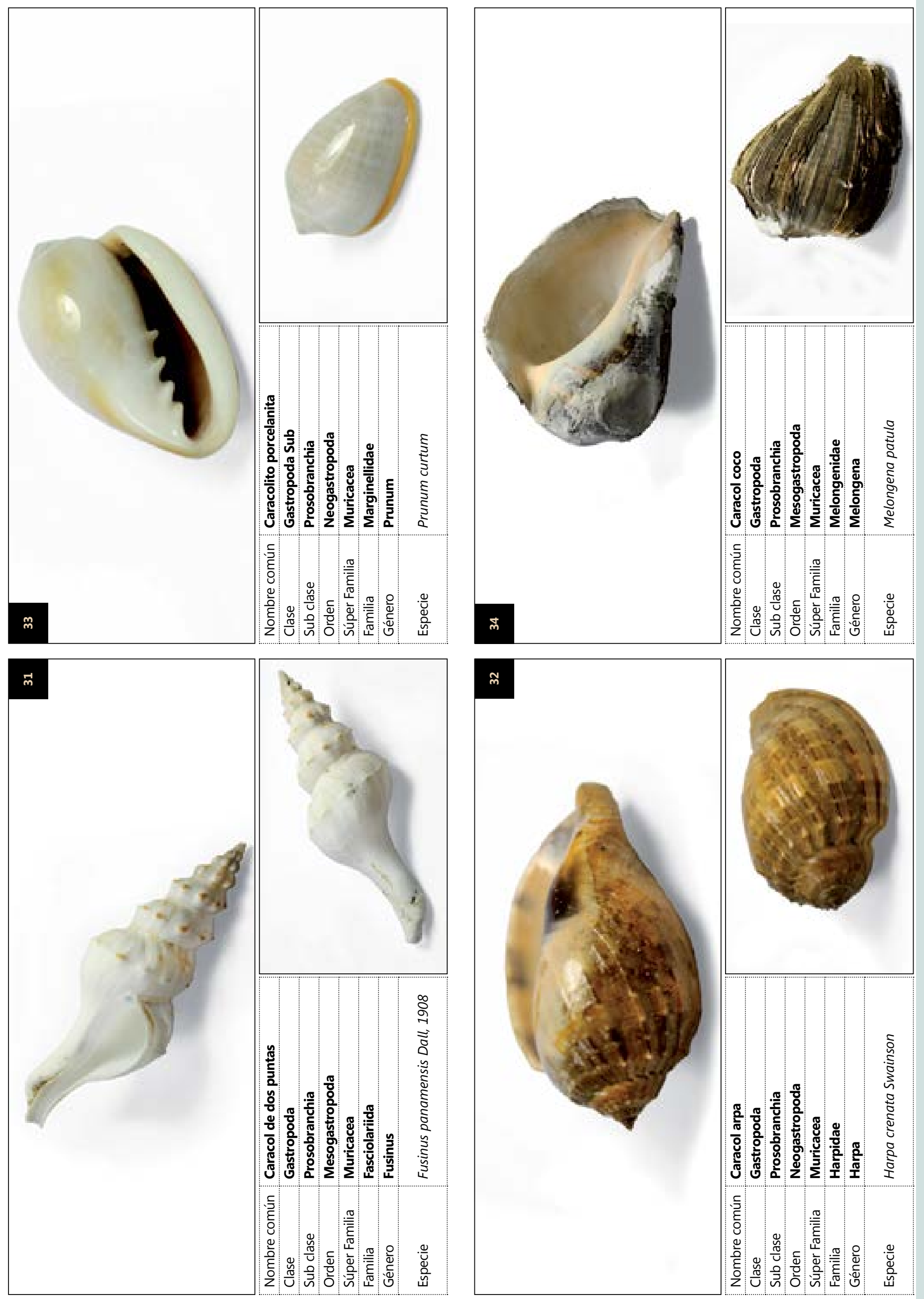




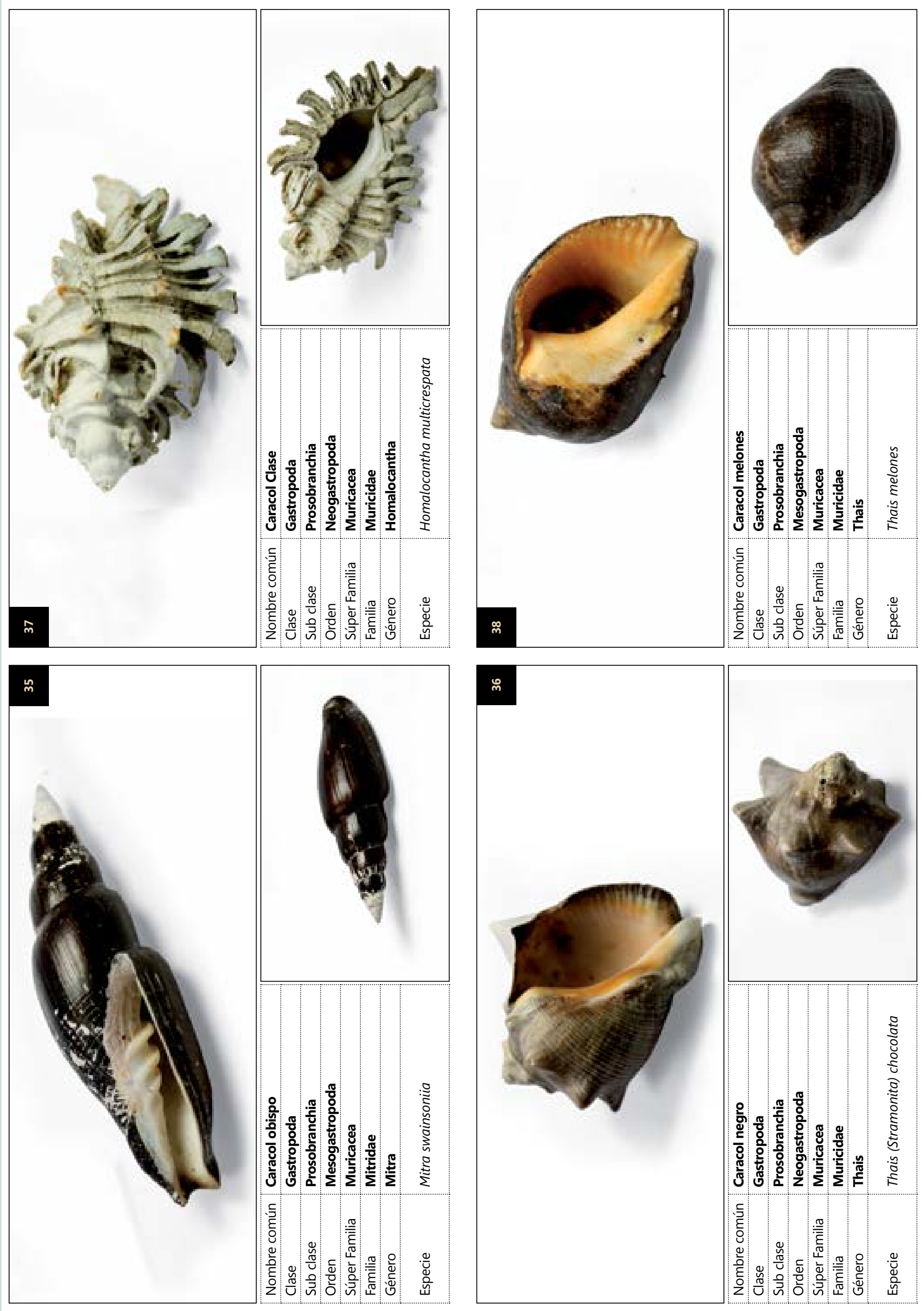




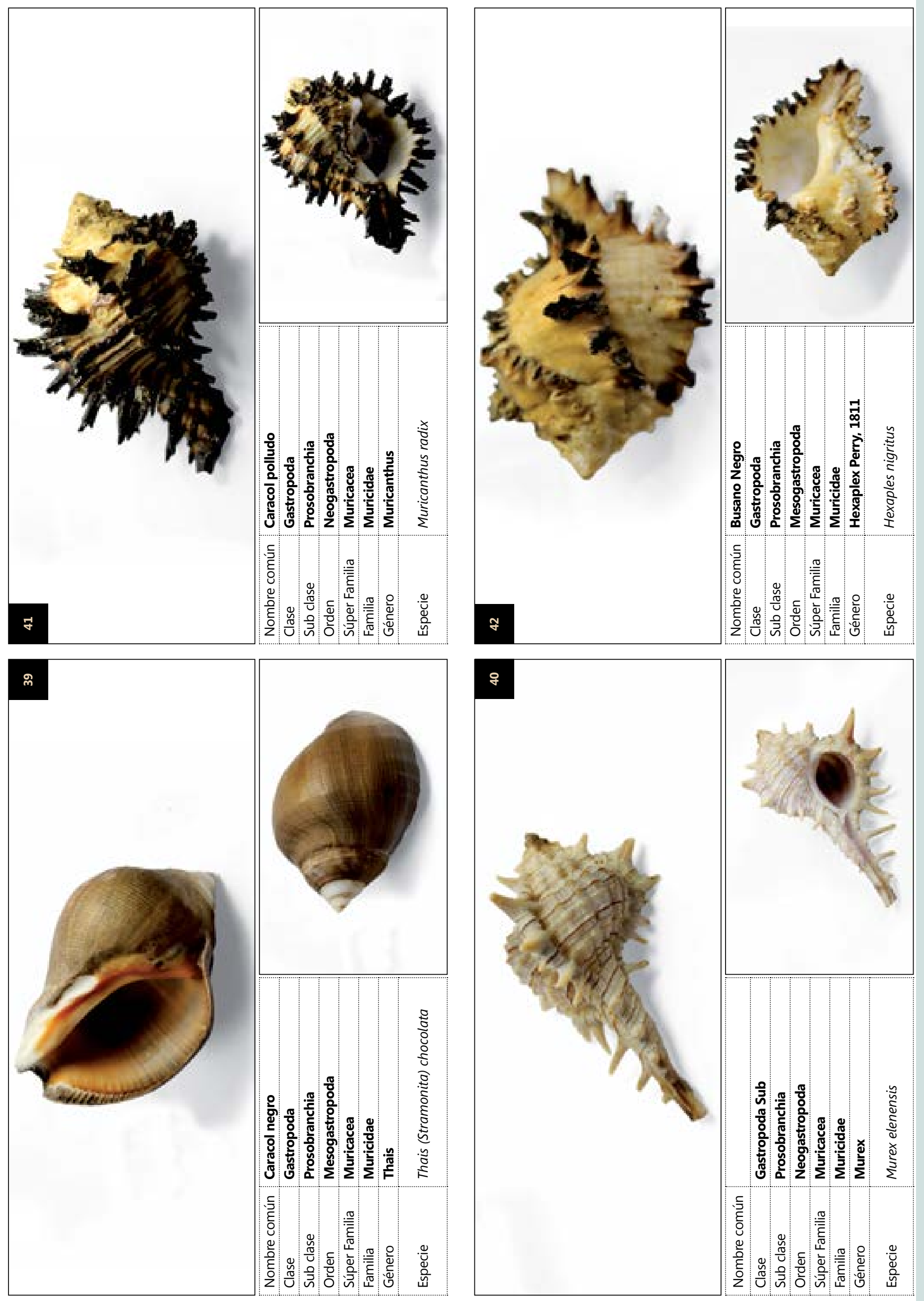




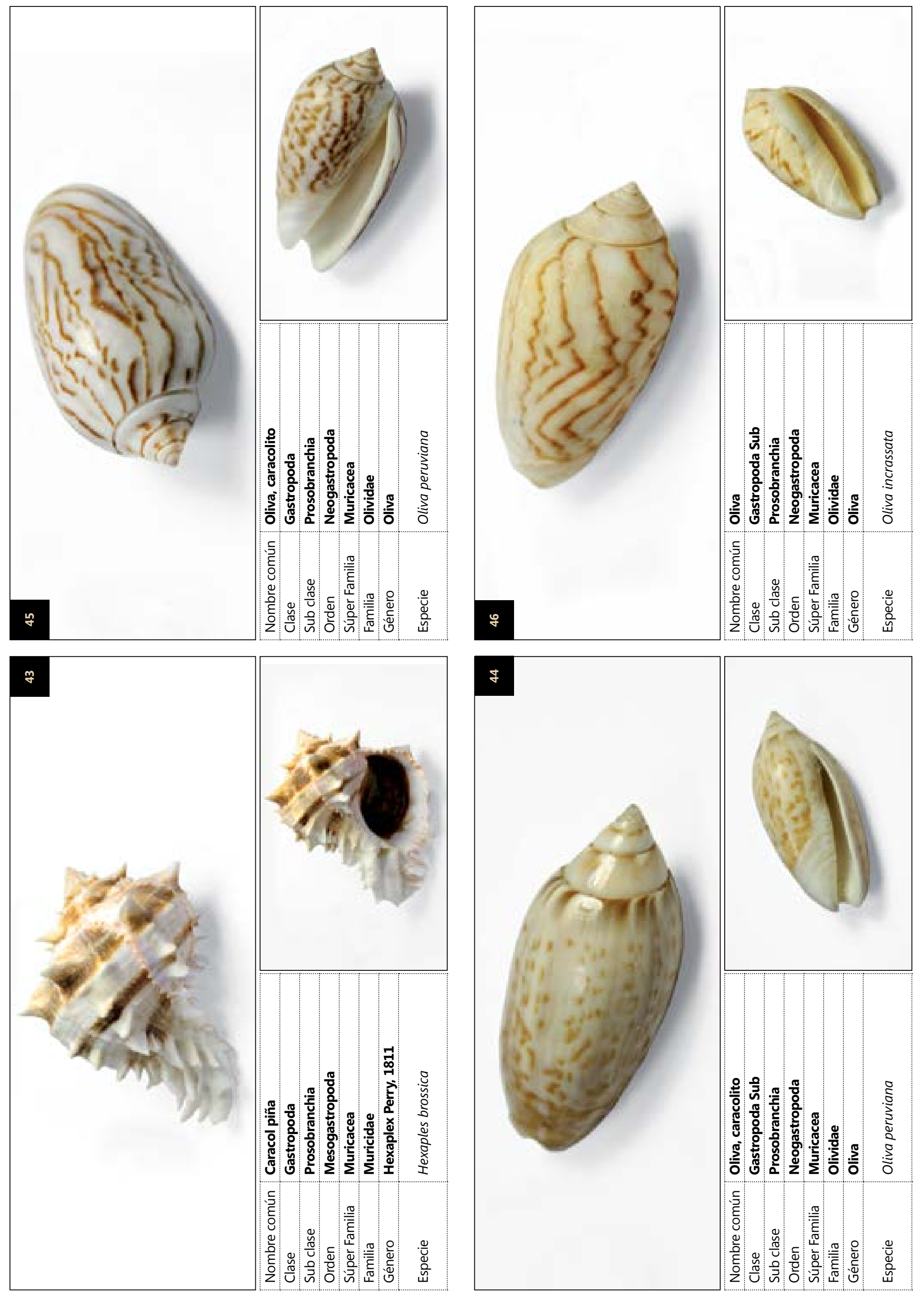




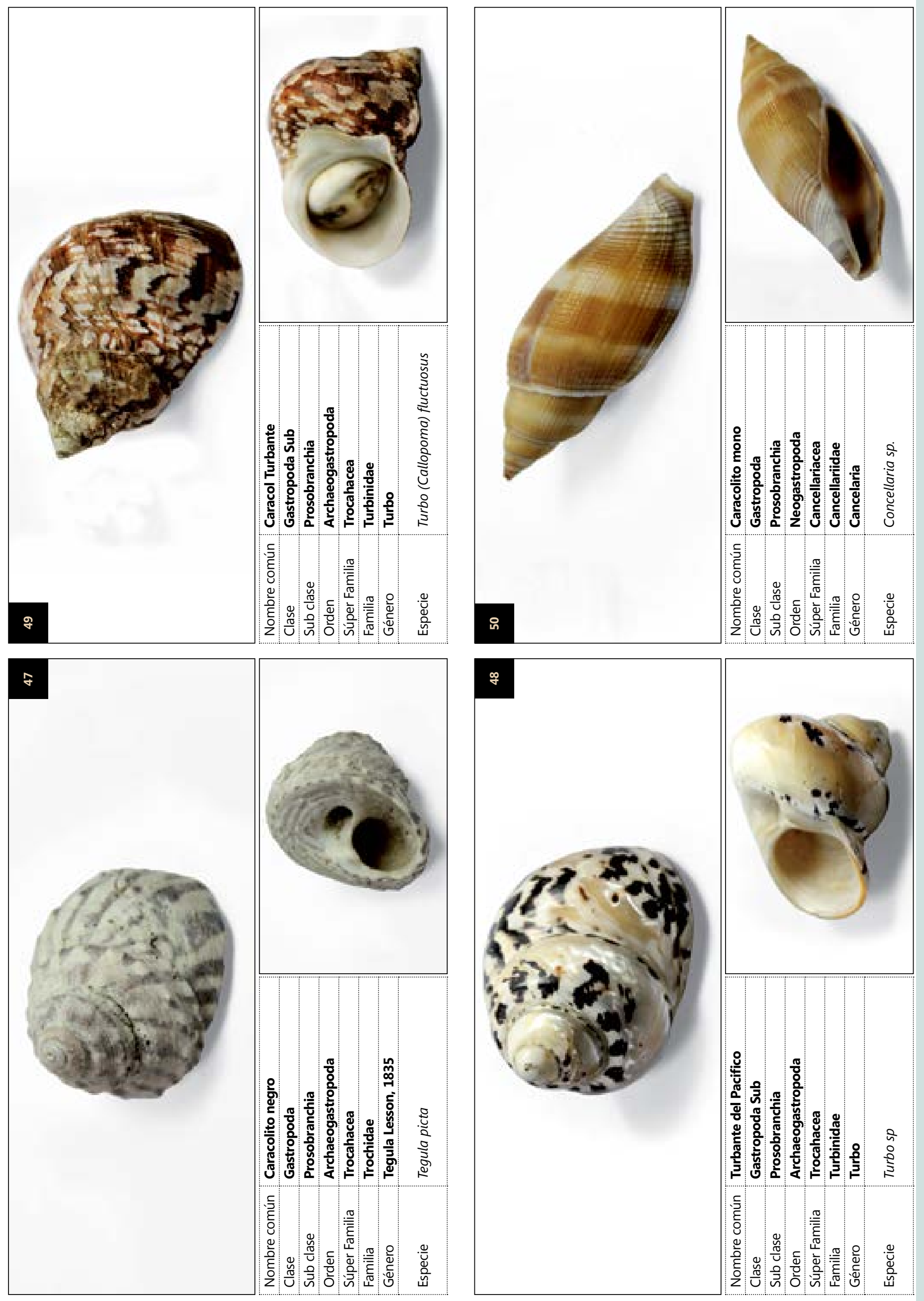




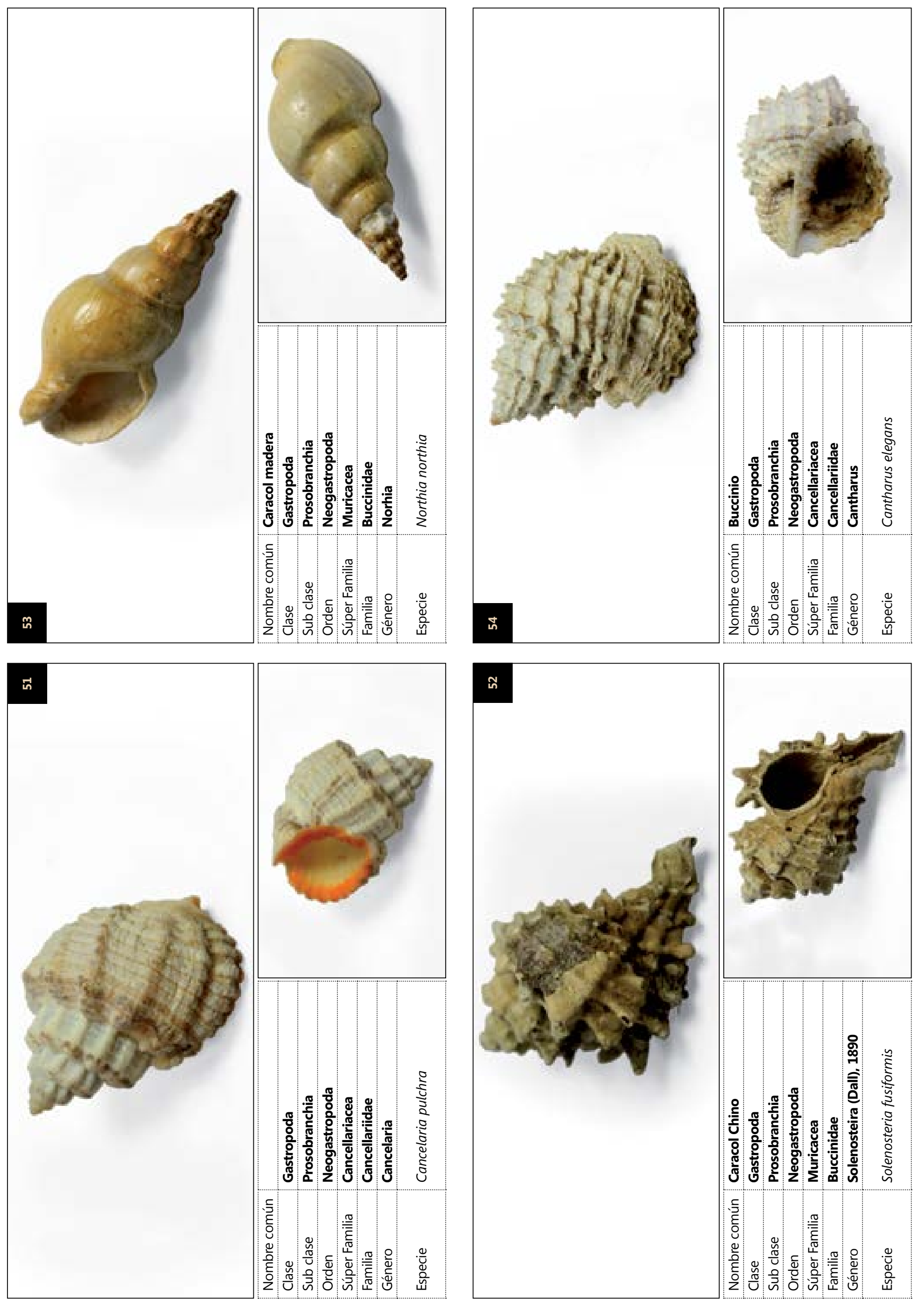




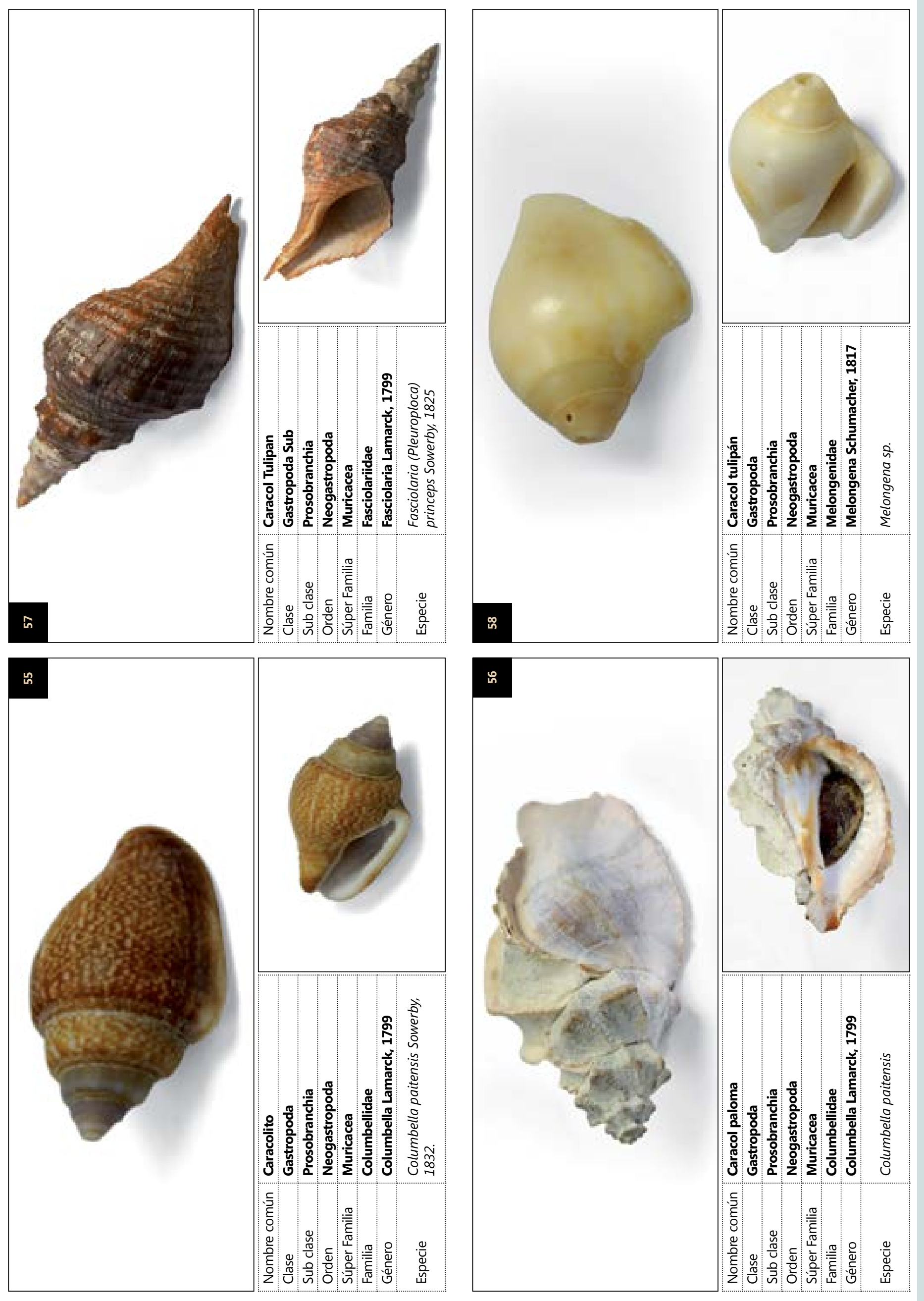




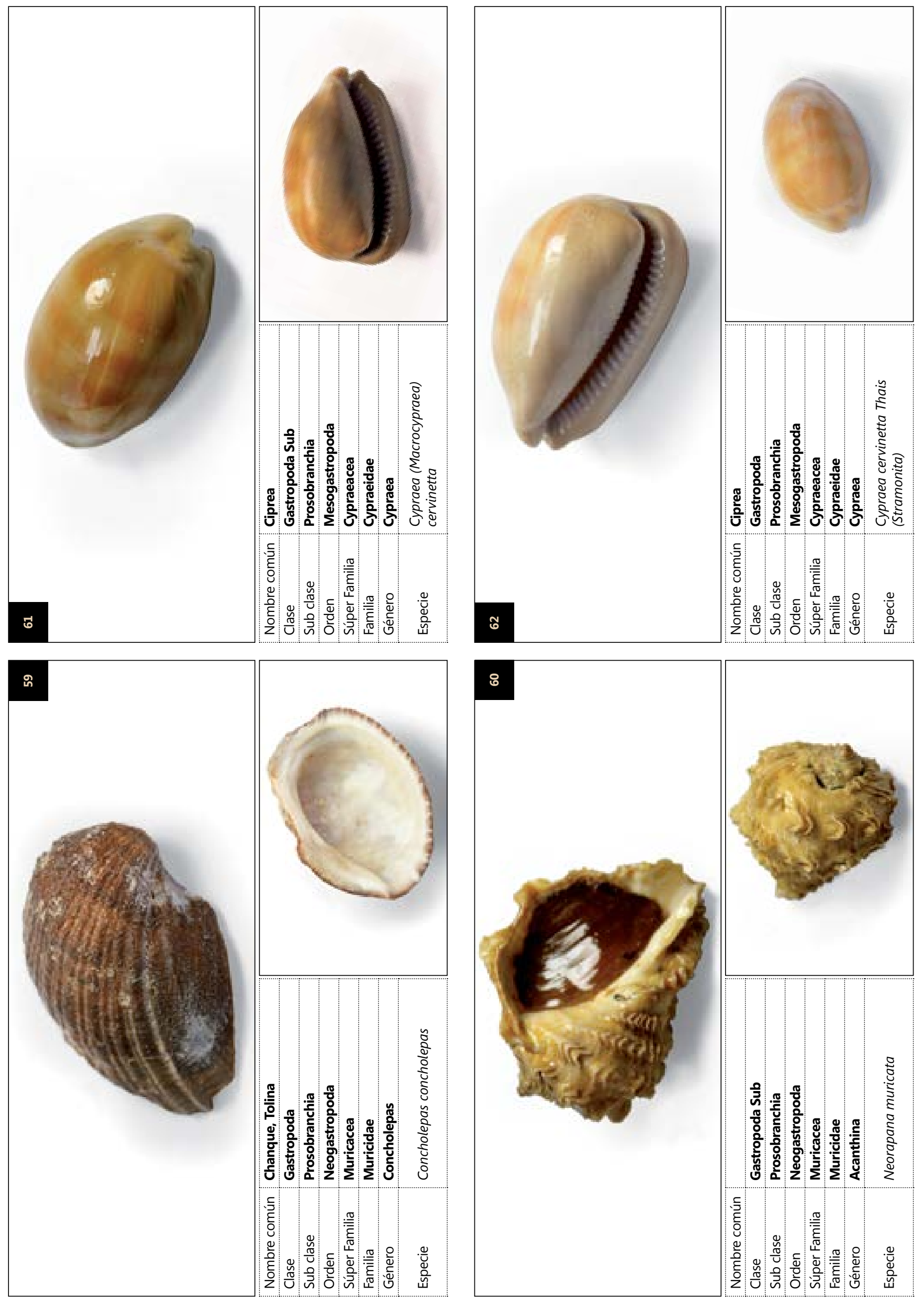




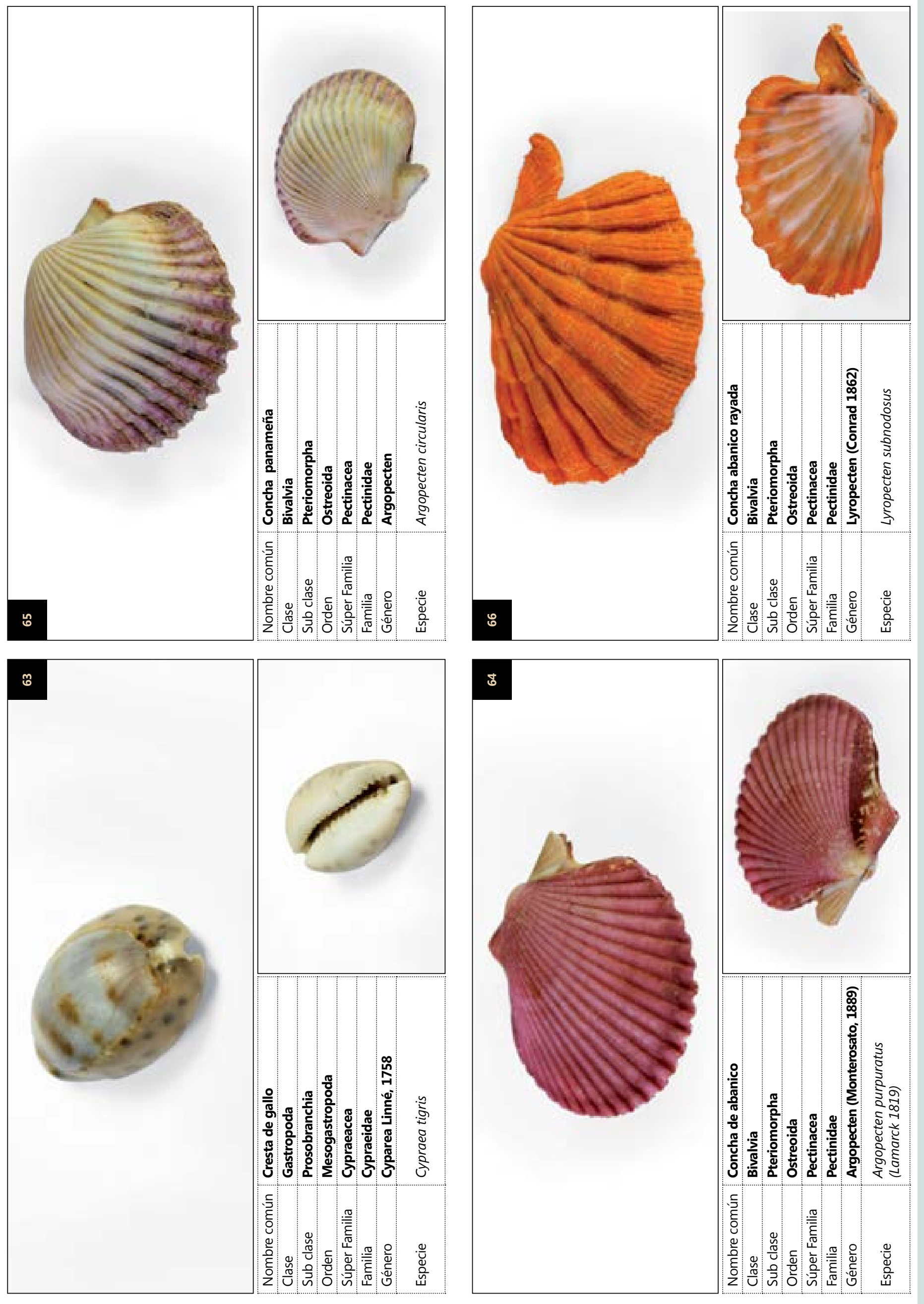



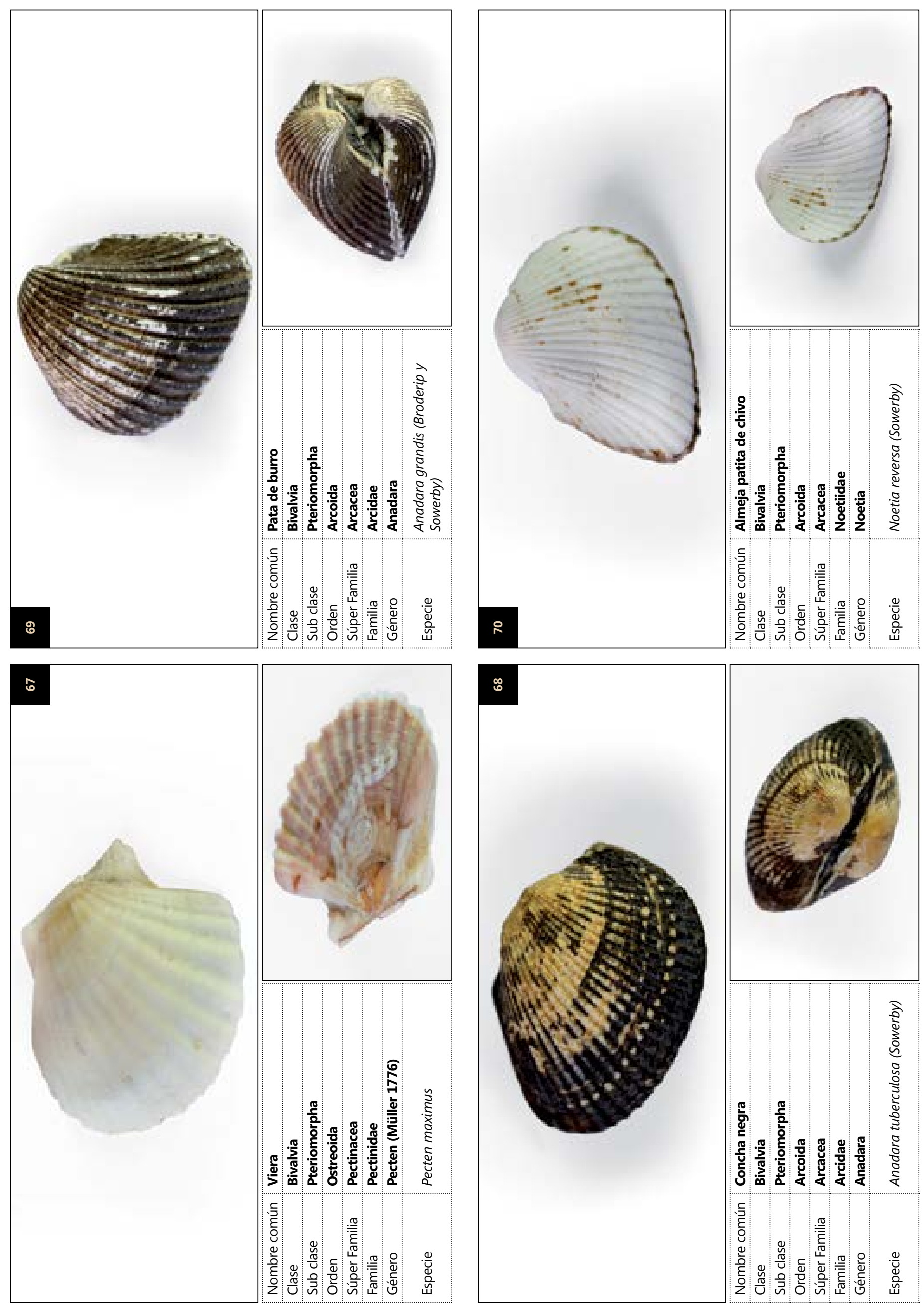

\section{ஜ}
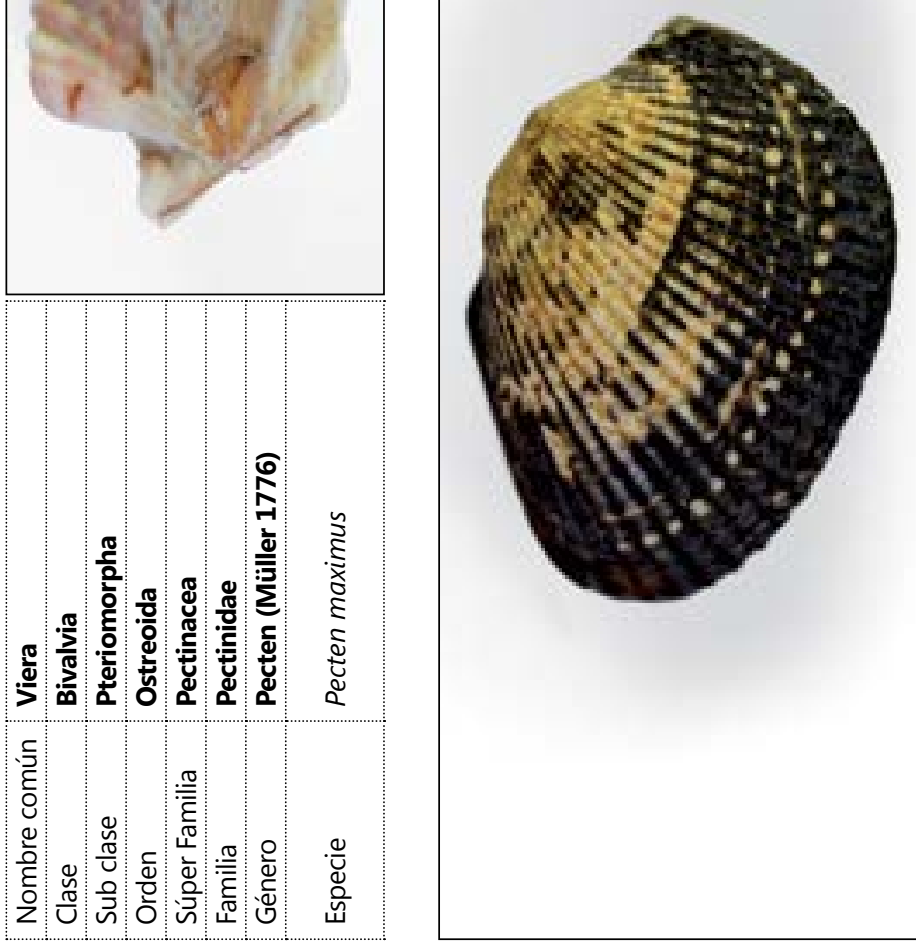

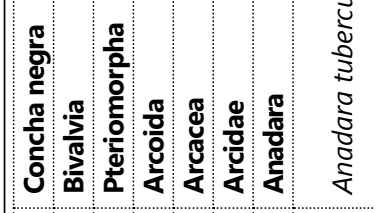

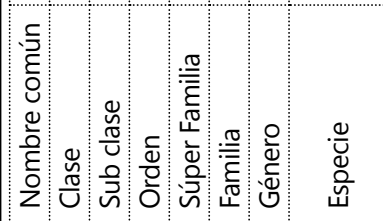




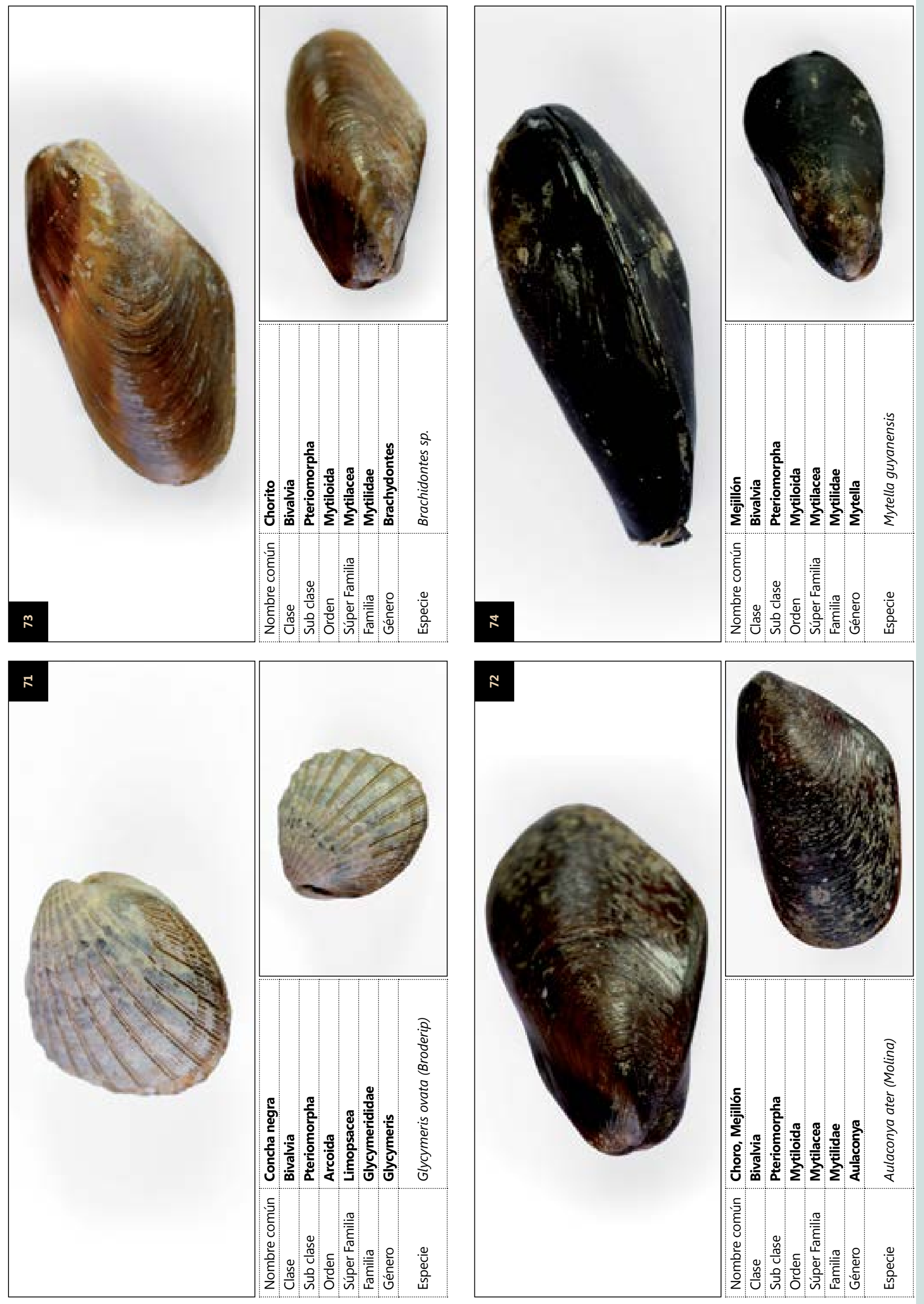




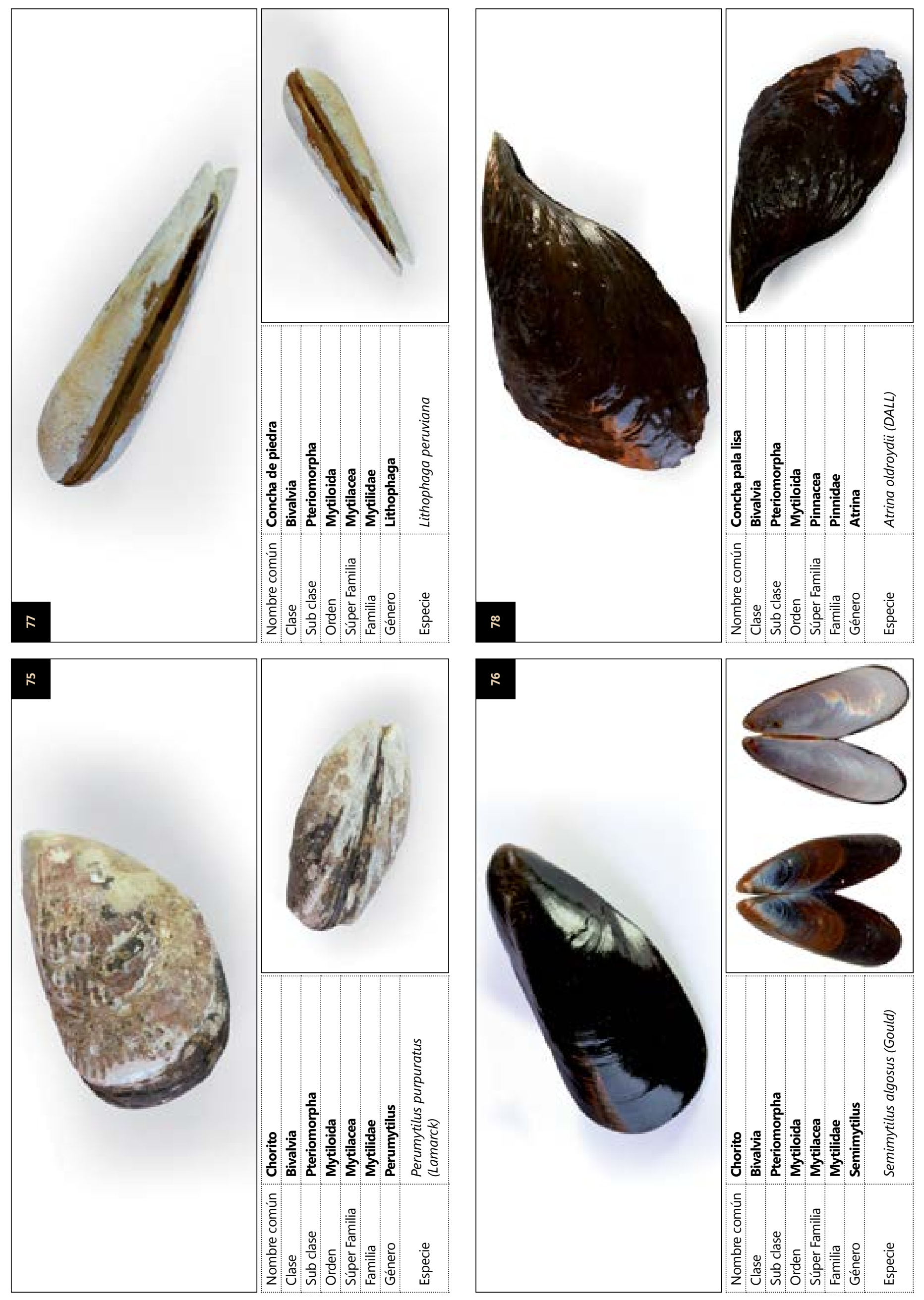




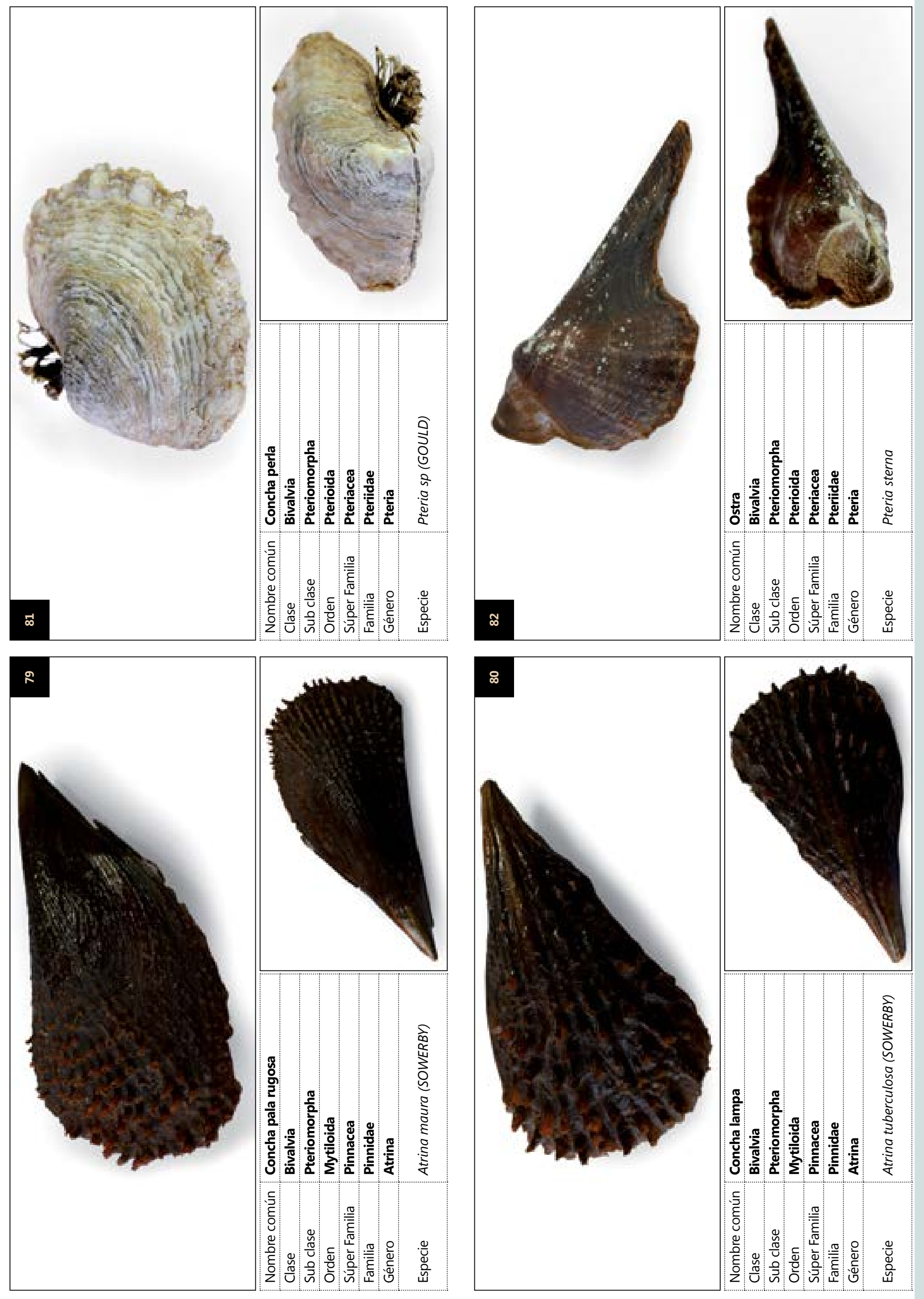




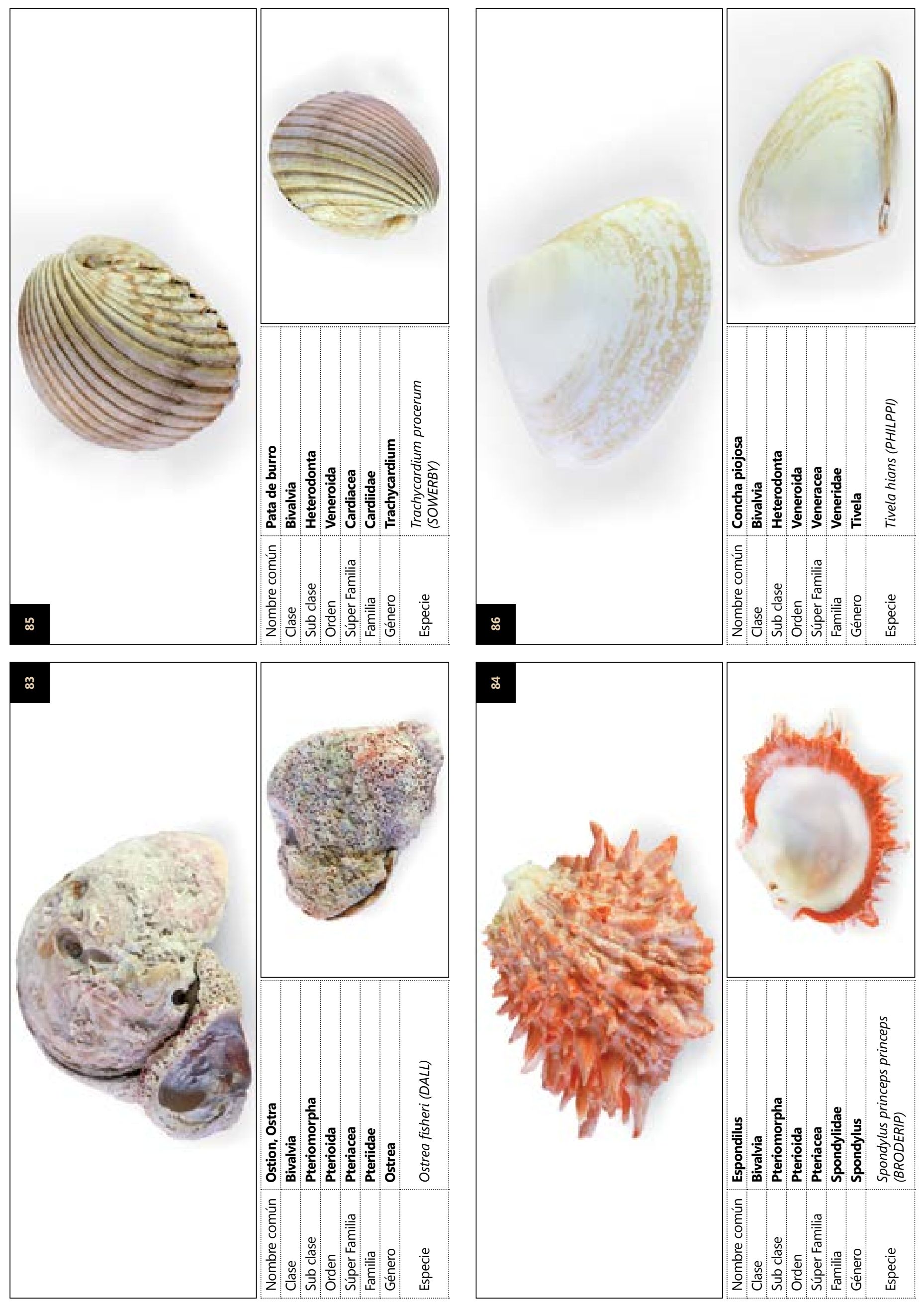




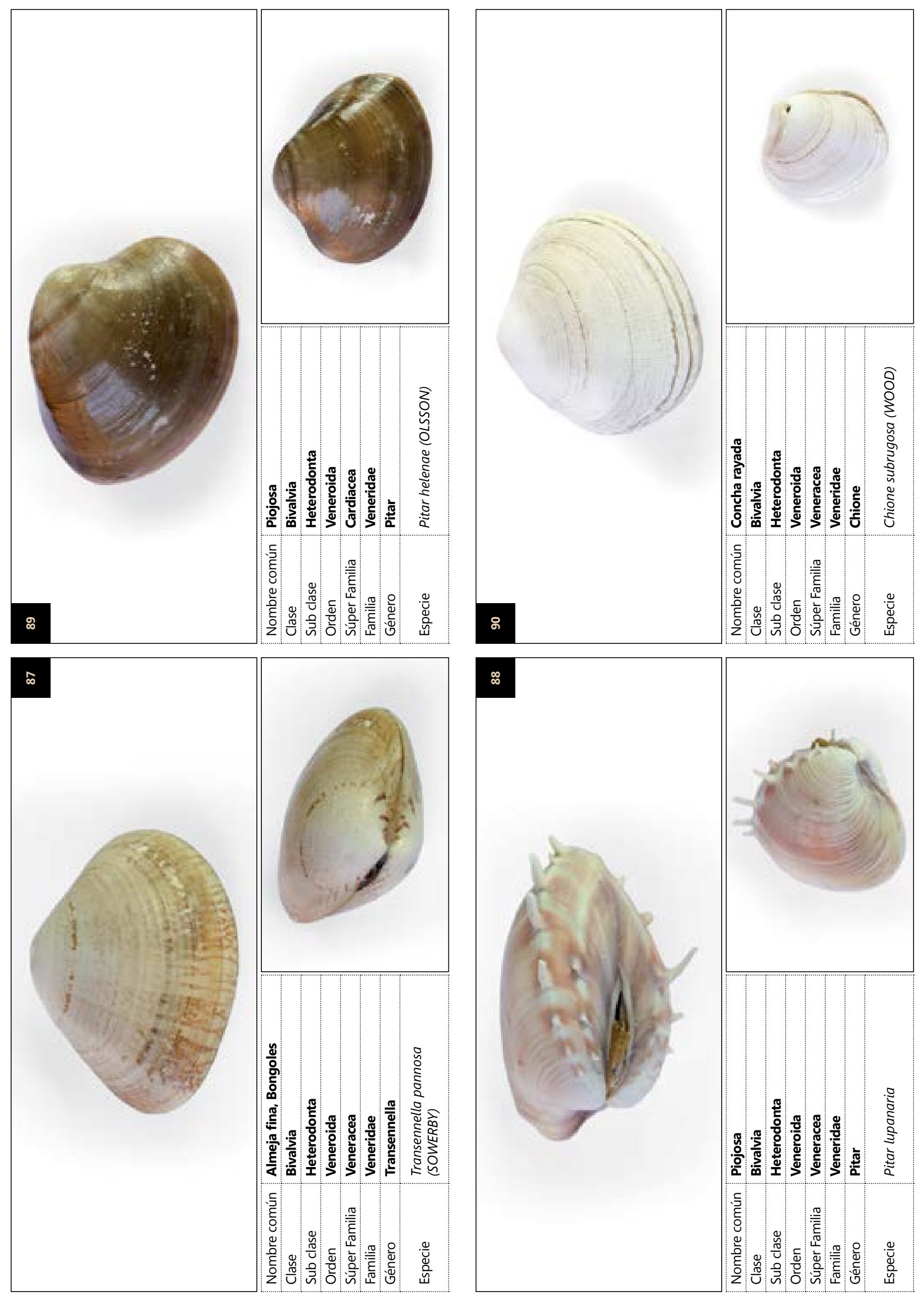




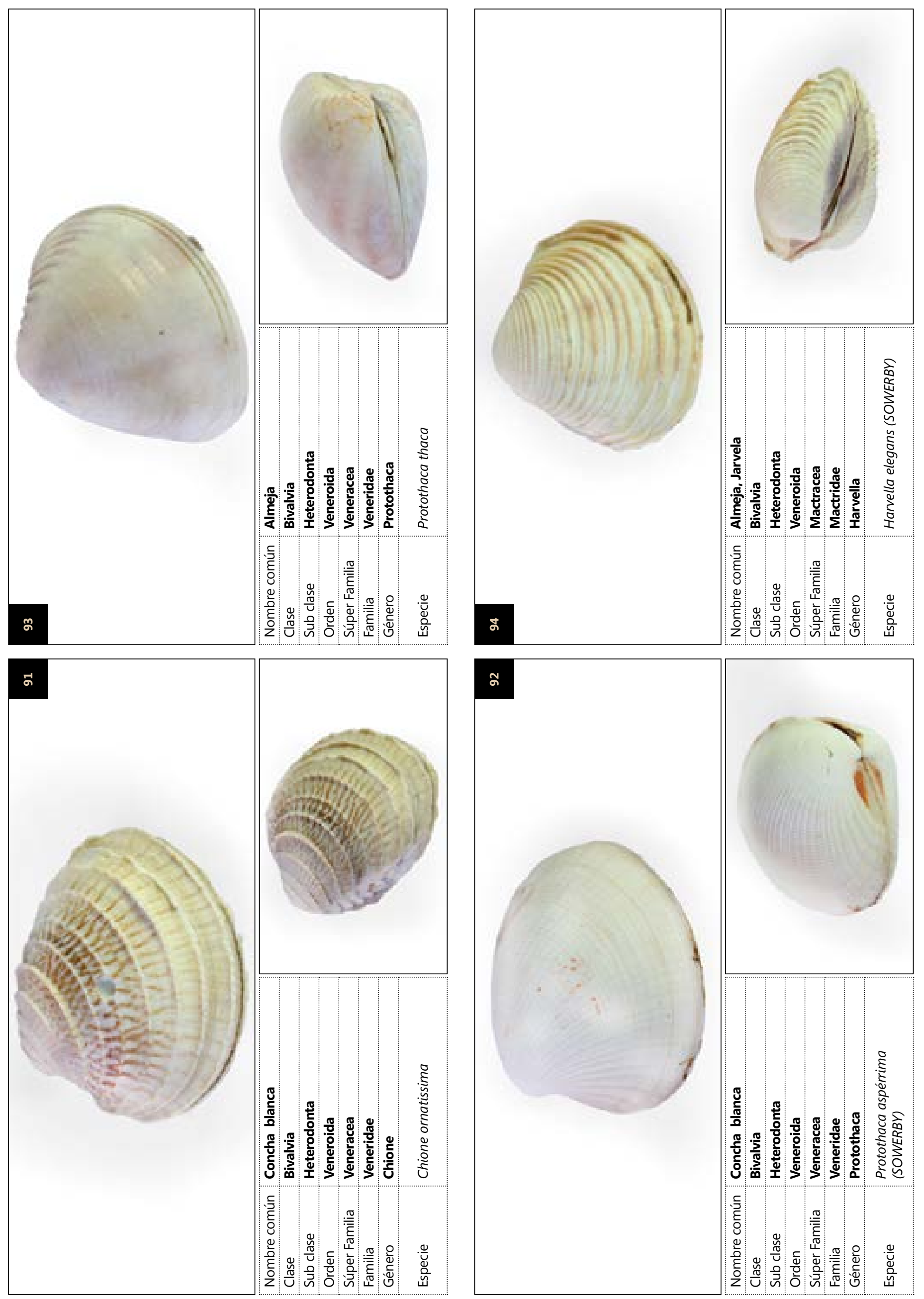




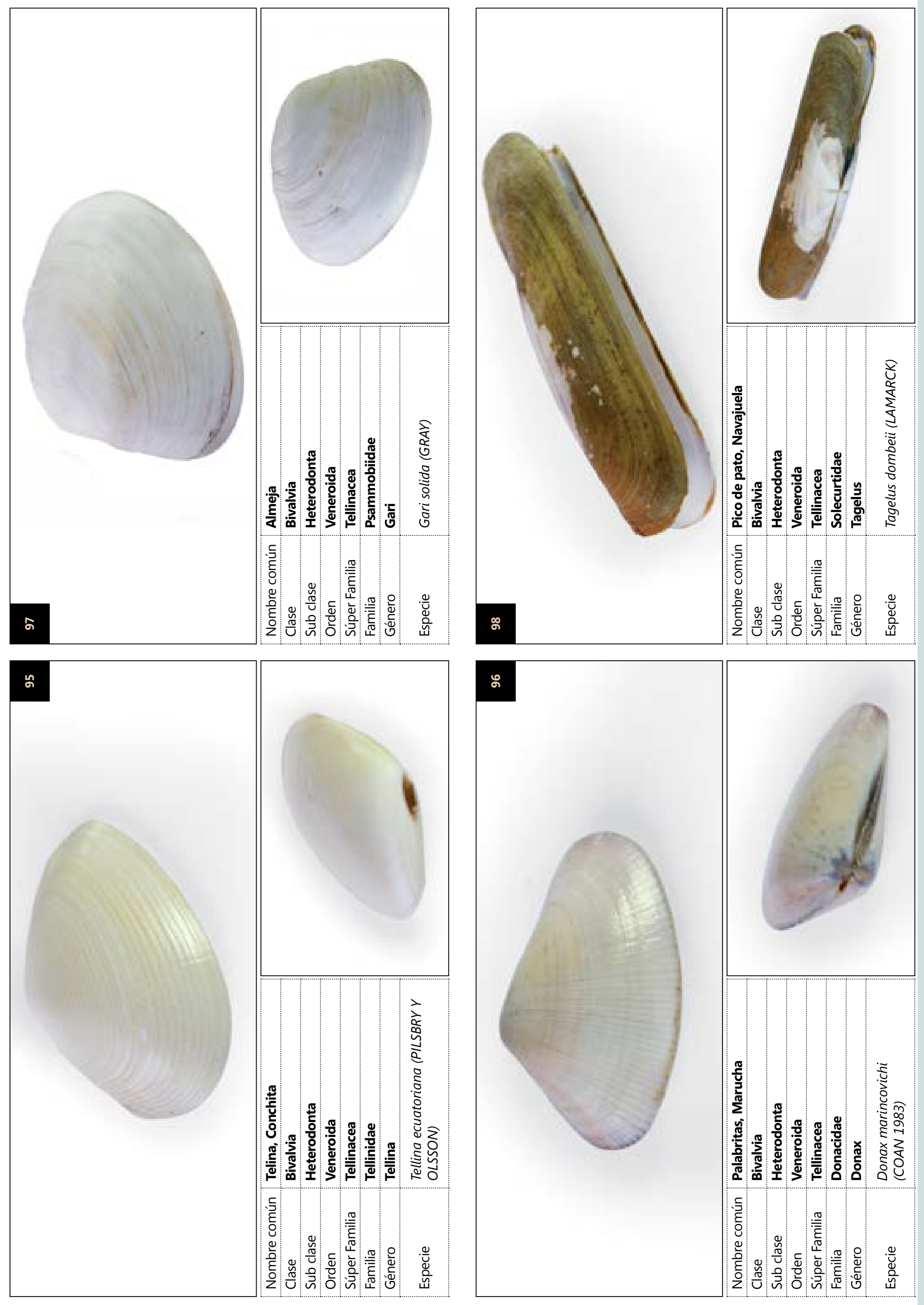




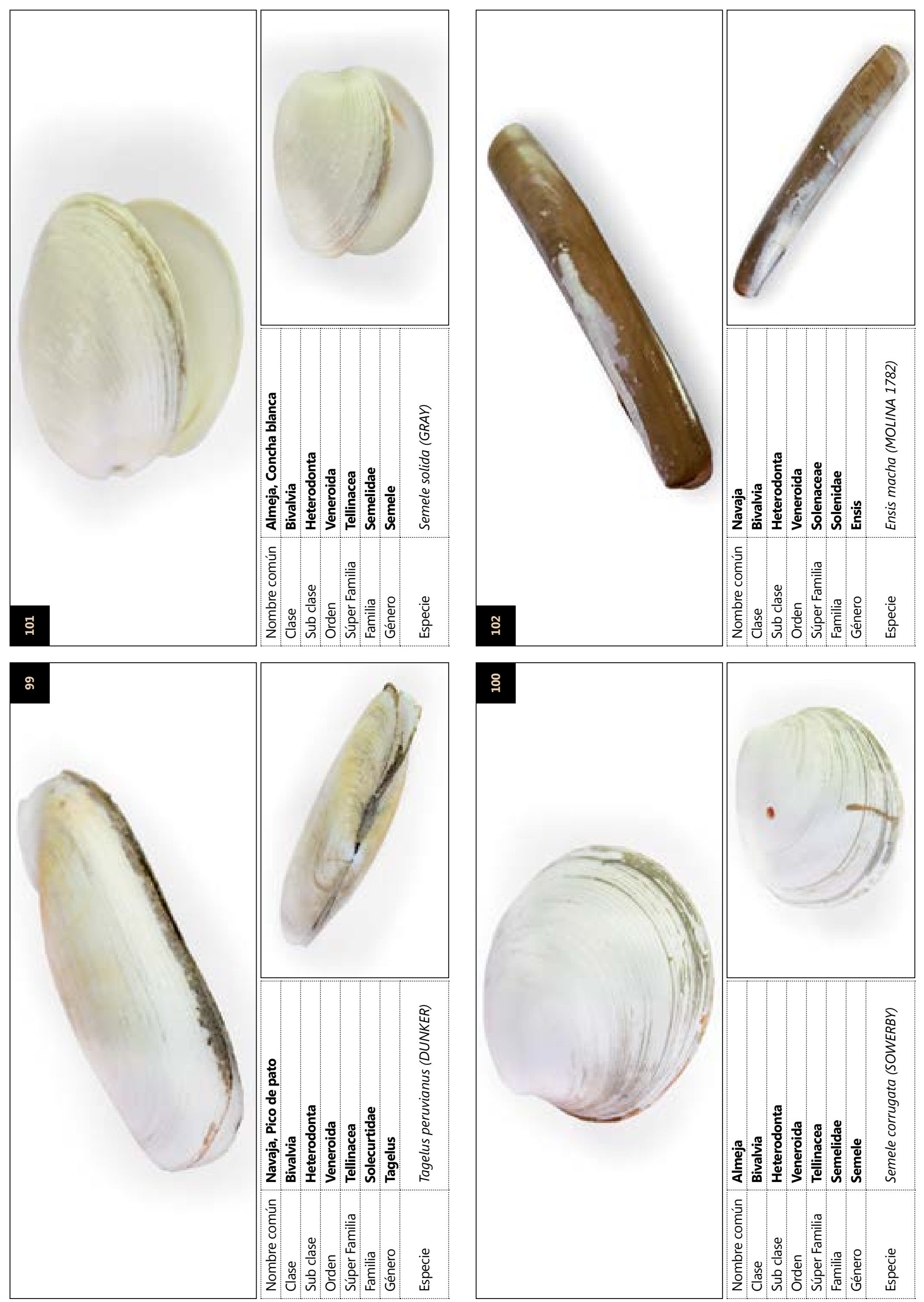




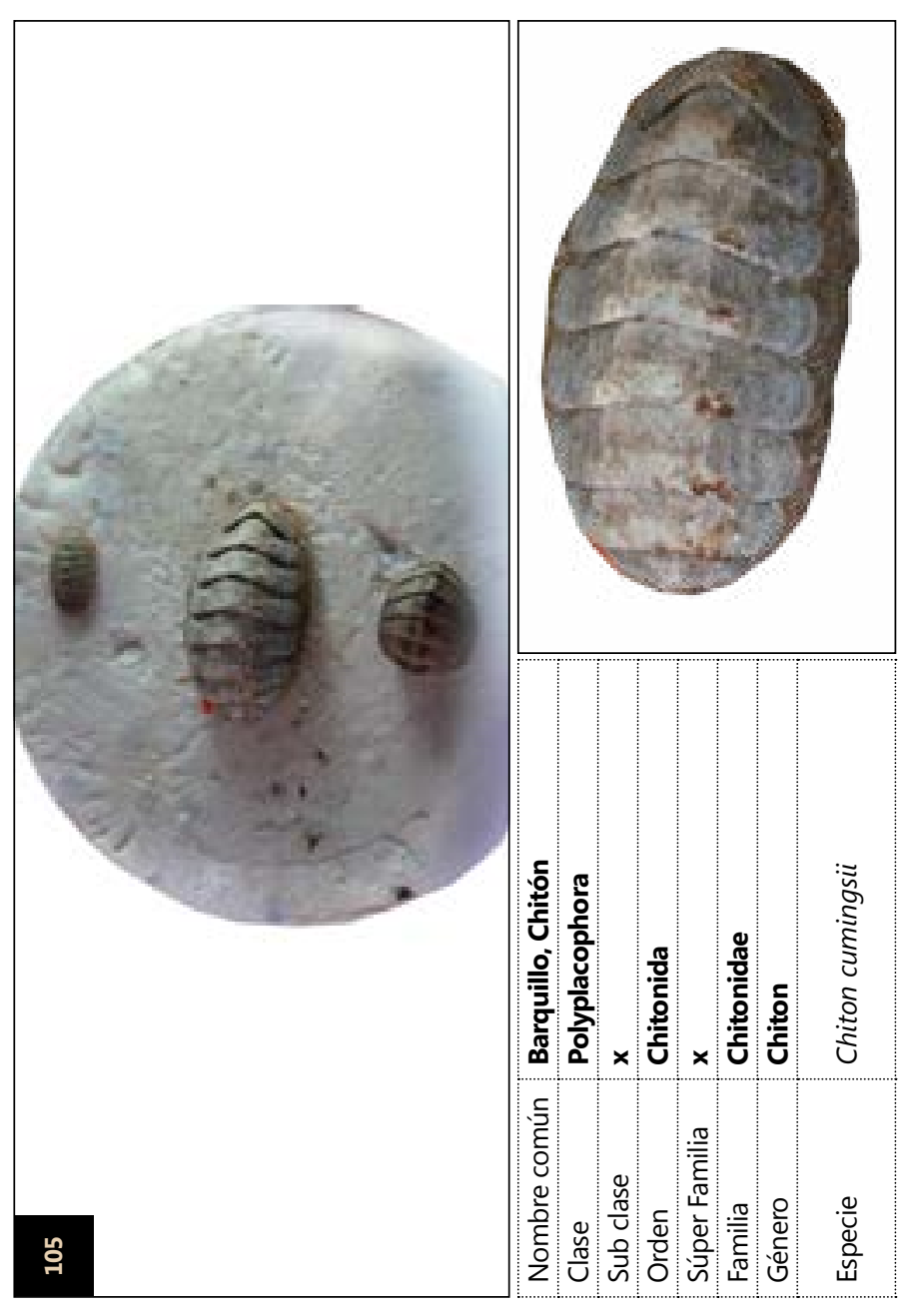

\section{$\stackrel{m}{\circ}$}

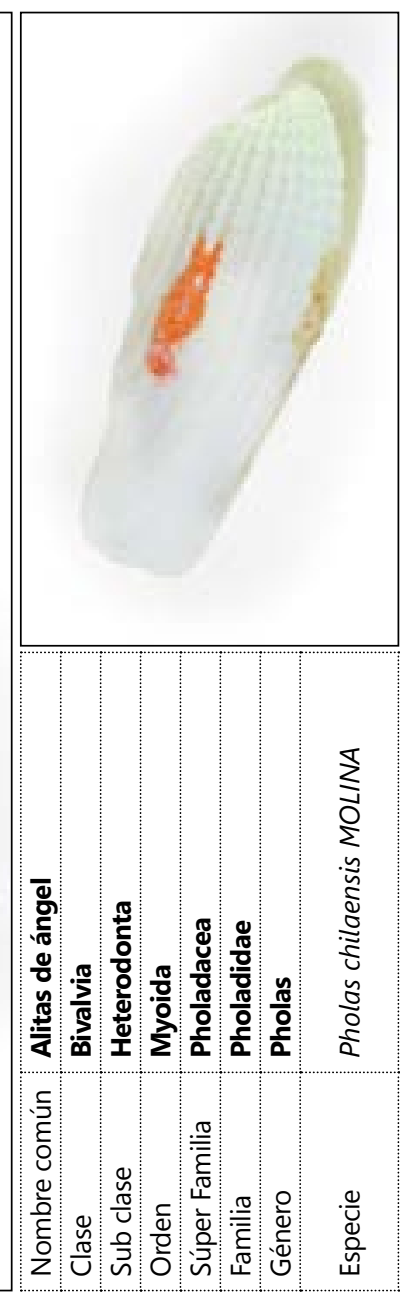

\section{帝}

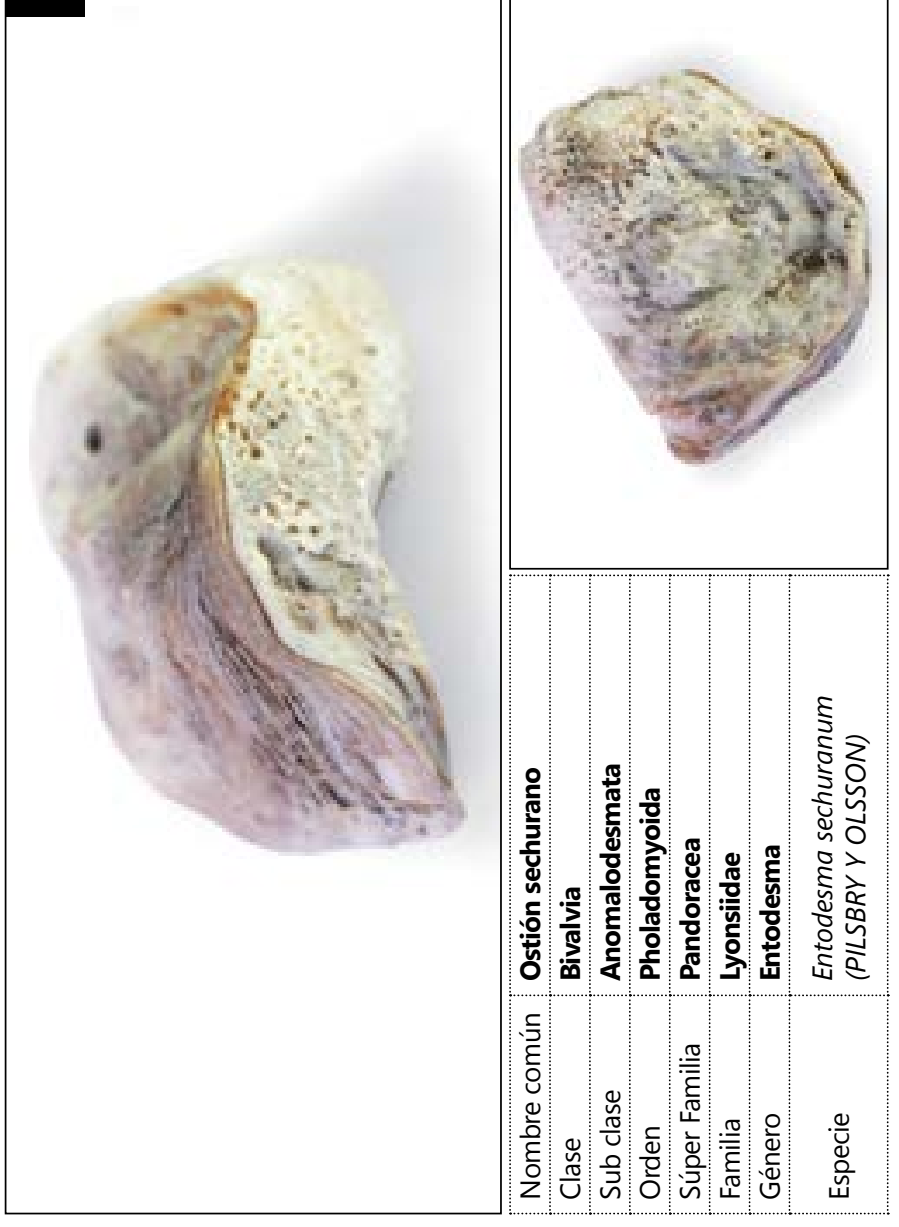




\section{DISCUSIÓN}

Si bien la concha de abanico es la especie de mayor presencia, por constituir la mayor fuente de trabajo y producción de los criadores artesanales, las demás variedades que se recolectan de manera natural no han sido objeto hasta el momento de proyectos de siembra regulada, desaprovechándose un medio de ingreso importante, por la gran demanda que tienen estas especies en la mesa familiar y restaurantes de la región para la preparación de platos criollos típicos y la gastronomía en general.

\section{CONCLUSIONES}

Las especies bentónicas identificadas han sido 105 , las mismas que en su mayoría constituyen fuentes de alimentación y de satisfacción de la demanda regional para la elaboración de platos típicos. No obstante, no se han desarrollado proyectos para su cría y producción comercial, y solo vienen siendo aprovechadas por recolección natural.

Debido a las condiciones de contaminación de la bahía, estas especies se encuentran en grave riesgo de extinción.

\section{REFERENCIAS BIBLIOGRÁFICAS}

- Bellido, Eleodoro. 1970. Mapa Geológico del Perú. Artículo incluido en el Atlas HistóricoGeográfico y de Parques Peruanos. Lima, Perú. pp. 117-119.

- Bernex, Nicole. 1987. La Geografía Regional del Norte. CIPCA. Lima, Perú. 120 pp.

- Caldas, Julio; Palacios, Óscar; Pecho, Víctor y Vela, Churchill.

- Deutscher Entwicklungsdienst. Oct. 2005. Estudio de caso: Declaración y plan de acción ambiental de la provincia de Sechura. Foro Ciudades para la Vida. Sechura, Piura, Perú. 125 pp.

- Deza Rivasplata, Jaime. 2001. ¿Se seca la costa? Fondo Editorial de la Universidad Alas Peruanas. Lima, Perú. 120 pp.

- Gobierno Regional de Piura. 2005. Plan estratégico de la bahía de Sechura y la isla de Lobos de Tierra - Diagnóstico. Gerencia Regional de Manejo Integrado de Recursos de la Zona Marino-Costera de Piura. Piura. Enero.

- Huapaya Cabrera, Blanca y Álamo Vásquez, Víctor. 1993. "Estudio malacológico de yacimientos arqueológicos del Macizo de Illescas y Bajo Piura”. En: Materiales arqueológicos del Macizo de Illescas. pp. 50-110. Pontificia Universidad Católica del Perú, Lima.

- Instituto Geográfico Nacional. 1989. Atlas del Perú. Proyecto Especial Atlas del Perú. Ministerio de Defensa.

- IMARPE 2005 - 2007. Laboratorio costero de Paita. Bols. 